\title{
Triple revolución en Ecuador. Contradicciones de la economía política frente a la construcción de un Estado Social
}

\author{
Germán Carrillo García \\ Universidad de Murcia
}

\section{Resumen}

Este trabajo plantea un detallado recorrido por las complejidades de la economía política en Ecuador. El abrupto camino hacia el establecimiento de un Estado Social en el país ha debido afrontar las múltiples contradicciones presentes en la sociedad andina y los apremiantes requisitos impuestos por el mercado global.

Palabras clave

Ecuador; economía política; Estado Social

Códigos JEL: N56, P48, B50
TRIPLE REVOLUTION IN ECUADOR. CONTRADICTIONS OF THE POLITICAL ECONOMY AGAINST THE CONSTRUCTION OF A SOCIAL STATE

Abstract

This paper sets out a thorough revision of the complexities of the political economy in Ecuador. In working towards establishing a Social State, the country had to confront the many contradictions present in Andean society as well as the pressing demands of the global market.

Keywords

Ecuador; political economy; Social State

JEL codes: N56, P48, B50

Fecha de recepción del original: 16 de diciembre 2018; 18 de octubre de 2019.

Germán Carrillo García, Universidad de Murcia. Departamento de Sociología. Facultad de Economía y Empresa. Campus Universitario de Espinardo. 30100 Espinardo (Murcia)

Tel.: +34 868884434; E-mail: gcarrillo@um.es.

ORCID ID: 0000-0003-2946-7432 


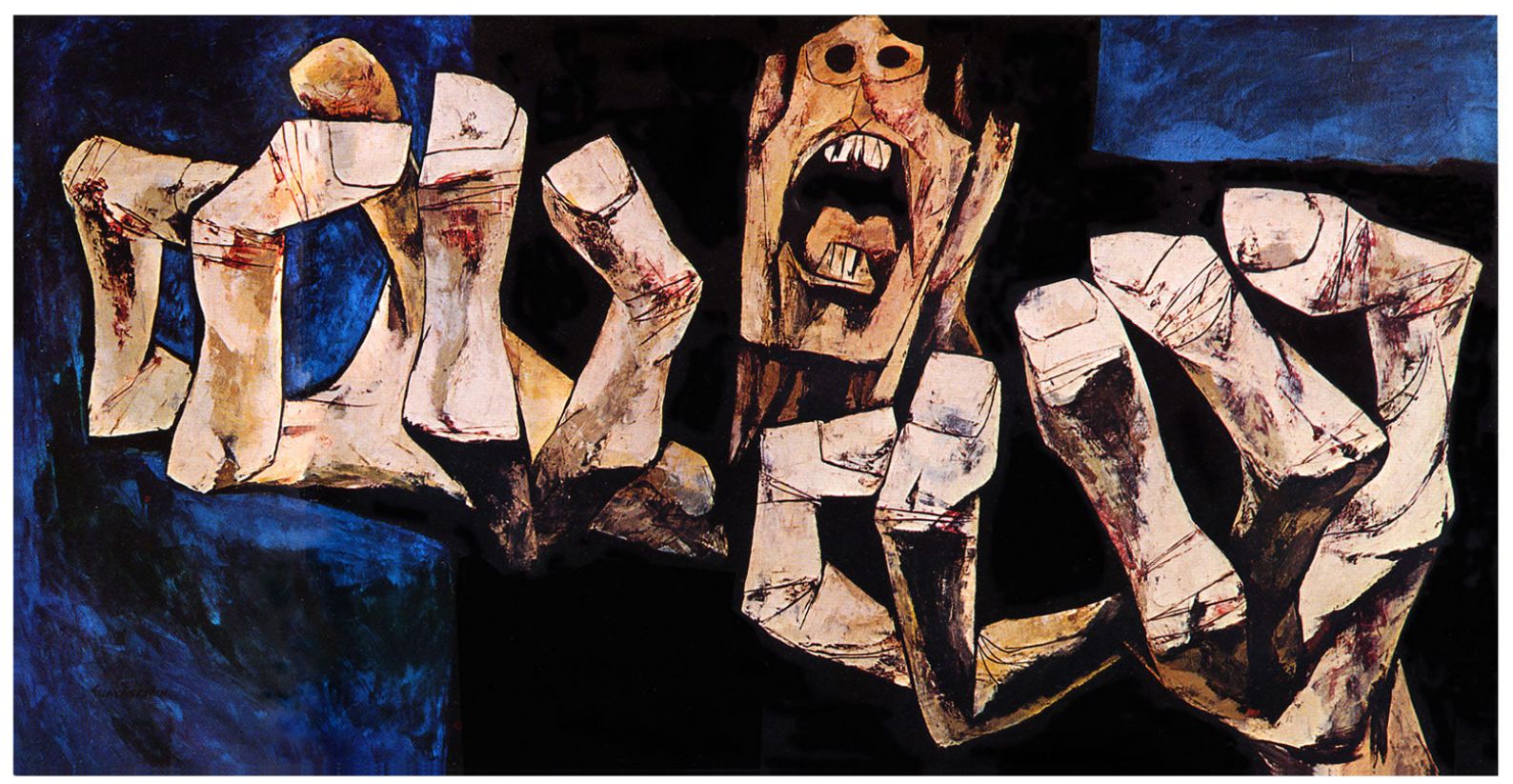




\title{
Triple revolución en Ecuador. Contradicciones de la economía política frente a la construcción de un Estado Social ${ }^{1}$
}

\author{
Germán Carrillo García \\ Universidad de Murcia
}

Introducción y método

Las fuerzas universalistas del movimiento obrero organizado han sido consideradas a la luz de la historia del socialismo el vehículo de transformación social por excelencia. Es terreno común partir de la secular contradicción entre capital-trabajo como proyecto político cuyo fin debe ser la superación de la "dominación del capital sobre el trabajo" a través de formas organizativas "en las que los trabajadores asociados controlen colectivamente su propio tiempo, su propio proceso de trabajo y su propio producto". Sin embargo, como afirma Harvey, "la larga historia de intentos de crear alguna alternativa de ese tipo (mediante cooperativas obreras, la autogestión, el control obrero y más recientemente las economías solidarias) sugiere que esa estrategia solo puede encontrar éxito limitado". ¿Por qué? La persuasiva respuesta que ofrece es deliberadamente metodológica: la contradicción capital-trabajo no es más que una de las "demás contradicciones del capital" (Harvey, 2014: 66). En lo que sigue analizaré la naturaleza de la evolución de las tensiones y contradicciones subyacentes entre la economía política y la economía social en Ecuador. Contradicciones frente a las cuales se han levantado, históricamente, alternativas e innovaciones políticas, económicas y sociales como intentos desesperados de resolver el tour de force secular entre capitalismo y democracia. Haré uso de la sugerente incitación del pensamiento hirschmaniano consistente en transgredir la tradicional consideración que restringe la ciencia económica al estudio de las "preferencias de primer orden", esto es, el intercambio de bienes y servicios, quedando relegado, por otro lado, a "psicólogos, sociólogos y antropólogos" la tarea de "tratar los complejos problemas" subyacentes de las "opciones observables en los mercados" (Hirschman, 1985: 8). Con el sintagma "triple revolución" he querido delimitar, por un lado, el marco temporal analizado que abarca los periodos comprendidos entre los decisivos años del desarrollismo de las décadas

\footnotetext{
${ }^{1}$ Trabajo realizado dentro del proyecto de investigación:"Entorno sociales de cambio. Nuevas solidaridades y ruptura de jerarquías (siglos XVI-XX)". (HAR 2017-84226-C6$1-P$ ). Financiado por el Ministerio de Industria, Economía y Competitividad. Gobierno de España.
}

sesenta y setenta del siglo pasado, tras las cuales comienza la era de las políticas de ajuste estructural y la "purga" de toda influencia keynesiana (Harvey, 2005: 29), hasta la reciente fase denominada neodesarrollista cuyo análisis verifica, una vez más, las contradicciones entre el incontrolado poder del capitalismo global y las debilitadas fuerzas políticas de acción estatal. Por otro lado, con el término revolución he querido subrayar, de acuerdo con Andrés Guerrero, el control hegemónico de las "poblaciones administradas" (Guerrero, 2010) ejercido casi siempre "desde arriba" a través del dominio coercitivo del aparato estatal y/o las clases elitarias, pero también por la instrumentalización funcionalista de aquéllos desplegada por la racionalización del mercado autorregulado. Elementos que juntos o combinados han erosionado, históricamente, la consolidación de una economía social y de una política democrática más madura en Ecuador, es decir, de un Estado Social.

Desarrollismo y "revolución desde arriba"

Refutando la teoría clásica del beneficio mutuo del comercio internacional, Raúl Prebisch y Hans Singer argumentaron (simultánea pero independientemente en 1950) la hipótesis contraria, a saber, la propensión secular de los "términos de intercambio" tendía a deteriorarse para los países productores y exportadores de materias y productos primarios e importadores de manufacturas. La hipótesis acudía irrevocablemente en defensa del "proteccionismo y la industrialización" y se sostenía sobre el andamiaje político de un "Estado juiciosamente intervencionista". Como sostendría Anwar Shaikh² casi medio siglo después, en contra de los apologetas del utopismo neoliberal, Hirschman en The Strategy of Economic Development (1958) rebatía las frágiles bases teóricas del capitalismo de mercado autorregulado. Para "combatir y neutralizar" las consecuencias del "efecto de polarización", es decir, la brecha que

\footnotetext{
2 Anwar Shaikh (2007) Globalization and the Myths of Free Trade. History, theory and empirical evidence, Routledge, New York. Obra de referencia heterodoxa en la que contribuyen autores como Ha-Joon Chang, Deepak Nayyar, Stephanie Seguino, Andrew Glyn, entre otros. Sin duda se trata de un refinado antídoto contra la autocomplacencia ortodoxa de la teoría económica estándar.
} 
separaba al núcleo central de las economías del capitalismo noratlántico de los países que englobaban a la heterogénea periferia mundial, Hirschman afirmaba que no debía eludirse la gestión política de la economía por parte de regímenes de planificación estatal. Desde esta perspectiva resultaba evidente que para escapar de la servidumbre de la dependencia, jno bastaba con aplicar una fórmula universalista! Los países que formaban parte de la periferia no responderían mecánicamente a los estímulos de la modernización, como tampoco adoptarían los diversos moldes esquemáticos del desarrollo como si se tratasen de "juguetes de cuerda que avanzaran en línea recta por las diversas etapas del desarrollo" (Hirschman, 1984: 27-39).

Crítica que podía aplicarse más enérgicamente a los abogados defensores de la modernización que a los paladines de la dependencia, aunque en cierto modo las recetas políticas de ambos podían mantener un diagnóstico común de la enfermedad. Los afilados argumentos de los teóricos de la dependencia, inspirados en el estructuralismo francés, centraron el análisis en las "estructuras y relaciones subyacentes en oposición a los epifenómenos". Observaron la economía mundial "como un sistema dentro del cual el centro y la periferia estaban intrínsecamente relacionados". Desde esta postura crítica, la mayor parte de los problemas que obstaculizaban el desarrollo de la periferia como, por ejemplo, una ralentizada productividad, la inflación o el desempleo, se asociaban a una "estructura económica específica" que emergió precisamente de la "interacción" entre el centro y la periferia. El diagnóstico admitía pocas objeciones: la debilidad de las políticas de industrialización se combinaba dramáticamente con un asombroso atraso agrícola continental (Palma, 2014; Hobsbawm, 2012).

De hecho se trató de una convicción ampliamente compartida por sectores económicos y políticos frecuentemente irreconciliables tales como la burguesía local y los "partidos comunistas ortodoxos", ambos grupos comprometidos con la industrialización y la abrogación del improductivo sistema latifundista (Hobsbawm, 2012: 360). Durante este contexto histórico la economía política no se fundamentaba todavía en la epifanía del mercado "autorregulado" y, por tanto, la acción política del Estado podía actuar como principal agente de transformación económica y social. Fue el periodo histórico denominado con el ambiguo término "desarrollista". Surgió de los ecos de la Gran Depresión de los años treinta y se fue apagando al finalizar la década de 1970 cuando la reductio ad absurdum del fundamentalismo de mercado penetró insistentemente contra la planificación de la economía política desintegrando el locus classicus del capitalismo de Estado. Al mismo tiempo constituyó un periodo histórico en el que cualquier movimiento político, revolucionario o no, podía ser interpretado como lo hizo Whitehead para la Revolución boliviana de 1952, a saber, como un esfuerzo desesperado por generar las bases que, en teoría, caracterizan al "moderno Estado-nación" (Whitehead, 2002). Sin embargo, con demasiada frecuencia, la política del aparato burocrático del Estado se hallaba (y se halla) estrechamente vinculada con la estabilización del orden político por parte de las clases elitarias. De hecho, cuando fallaba el control hegemónico, en el sentido gramsciano, se acti- vaban inmediatamente los controles estatales coercitivos con el fin de evitar el riesgo de las consecuencias políticas de indeseadas subversiones que podían emerger, y de hecho emergieron, de los sectores sociales más desfavorecidos del cuerpo social. Por ello, como sagazmente afirmó Hirschman, la modernización "desde arriba" fue más la "norma que la excepción" en Latinoamérica (Hirschman, 1984: 172-173).

Todos los aspectos apuntados iban a conjugarse en la configuración política del desarrollismo en Ecuador. Los campos de batalla ideológicos dictados por la Revolución cubana (1959) y su respuesta política enarbolada por la Administración de John F. Kennedy (1961-1963) conocida como "Alianza para el Progreso" (1961-1970) se ajustaron con la crisis que precipitó el fin del virtual decenio de prosperidad de 1950 en el país andino, cuyo crecimiento económico había sido abonado por el sector externo del cultivo de banano. Durante los dos decenios siguientes, burócratas y militares aliados con "terratenientes serranos y agroexportadores, banqueros e industriales y grandes comerciantes serranos y costeños" junto al incondicional apoyo de la CIA y una parte reaccionaria del clero (que manipuló las "devociones populares"), llevaron a cabo su particular desarrollo "estatista y nacionalista" (Andrade, 2009: 236-237; Ayala Mora, 2002: 280). De este modo, tras inmunizar los riesgos sociales subversivos, las grandes concepciones estructuralistas sobre la reforma agraria y la industrialización iban a colmar holgadamente los intereses particulares de las clases gobernantes, socavando al mismo tiempo las esperanzas de edificar las bases políticas de un Estado social menos hostil a distribuir la riqueza económica y la igualdad política. La "nueva anatomía de la sociedad civil", como diría Marx, estaba delimitada por una pavorosa desigualdad y pobreza.

Hacia la segunda mitad del siglo XX algo más del 75\% de la población ecuatoriana, ligeramente superior a los tres millones, habitaba en zonas rurales. Su supervivencia económica, cuando no dependencia del régimen de "semi-esclavitud" conocido como huasipunaje (Guerrero, 1988; Marchena, 2006) ${ }^{4}$ ampliamente extendido por las haciendas del altiplano andino, se basaba en la explotación de pequeñas parcelas o minifundios cuya exigua producción se dirigía casi en exclusiva al consumo doméstico y, como mucho, al comercio local. La concentración de la tierra era abrumadora y el trabajo servil en las haciendas serranas apenas había sido alterado desde el último tercio del siglo XIX. El primer censo elaborado en 1954 había mostrado que probablemente en torno a un millar y medio de propietarios poseía casi la mitad de la tierra agrícola del país; por el contrario, y confirmando la desigualdad, una cuarta parte de los productores disponía de algo menos del 1\% del suelo agrícola (Casals, 1965; CIDA, 1965; Larrea, 2008). Naturalmente, para combatir estas abyectas condiciones eco-

\footnotetext{
${ }^{3}$ Caben pocas objeciones acerca del tipo de desarrollo económico que se propugnaba desde Washington para América Latina. De acuerdo con Fontana, la "retórica de la Alianza para el Progreso" se combinaba con la aprobación de un "plan de acción global contra la insurgencia subversiva en América Latina". Véase Fontana (2011: 505).

${ }^{4}$ En síntesis, el huasipunaje consistía en una parcela de tierra entregada por el gamonal o señor de la hacienda, de donde el campesino indígena obtenía los recursos tanto para su propia subsistencia como para la de su familia, "siendo ésta una ampliación que trascendía los lazos de consanguinidad hacia relaciones incluso de carácter ritual". Véase Guerrero (1988).
} 
nómicas y sociales el instrumento político más eficaz no era otro que el reparto agrario. Sin embargo, en un país con una composición social controvertidamente indígena el acceso a la propiedad de la tierra iba a permanecer resguardado dentro de las fortalezas político jurídicas de las clases hegemónicas, erigidas sobre los cimientos del racismo.

Como quedó demostrado desde la sanción de la primera Ley de Cooperativas de 1937, cuando se incitaba explícitamente el "desarrollo de la comunidad", afirma perspicazmente Almeida, no se buscaba potenciar los valores tradicionales de las comunidades indígenas porque, contrariamente, la "instauración de sociedades o cooperativas agropecuarias" mantenía una clara orientación hacia la "economía de mercado" (Almeida, 2003: 96). Y es que, de acuerdo con Bretón, cualquiera que fuese la versión del progreso aplicada a través de la política gubernamental o de las agencias internacionales, las concesiones de cualquier índole a aquellas "formas de vida" que no se ajustaran explícitamente a los "parámetros de la modernidad" quedaban fuera de toda consideración política (Bretón, 2013). Una concepción del desarrollo obstinadamente lineal y etapista que ha sido ampliamente consensuada, tal como veremos, tanto por los utópicos neoliberales como por aquellos sectores intelectuales y colectivos sociales que pretendían (como pretenden) subvertir la lógica del fetichismo de mercado. De esta manera, el campo de la política burocrática estatal acompañado por agencias de desarrollo, principal aunque no exclusivamente norteamericanas, precipitó un ciclo reformista agrario durante los decenios de 1960 y 1970 que si bien actuó como corrosivo contra el vetusto edificio de las relaciones sociales y económicas precapitalistas allí donde todavía eran predominantes (especialmente en el altiplano andino), no alteró la tenencia de la tierra y, precisamente por ello, su corolario no fue otro que el de introducir una modernización eminentemente anti-campesina (Andrade, 2009: 236-237).

¿Cómo, en todo caso, debemos interpretar que a pesar de la amplia difusión de organizaciones cooperativas, que recalcó insistentemente la retórica reformista, no se consolidara como un régimen agrario alternativo al tradicional con el fin de actuar como motor de transformación de la economía? En cierto modo, la clásica respuesta a las tensiones entre capital-trabajo basada en la organización en cooperativas se limitó de forma excesiva a actuar como mero prerrequisito jurídico para iniciar el proceso de "adjudicación de tierras"; una vez que este trámite burocrático se consumaba las cooperativas tendían a subdividirse en parcelas (minifundios) con escasa viabilidad económica. Aunque hubo un intento importante de transferir tierras al elenco campesino, tributario de los hacendados exactores o sus administradores, especialmente entre las haciendas de propiedad fiscal (Martínez Valle, 2016), una cosa es distribuir la tierra o asumir su incautación por parte del campesinado y otra completamente diferente es someter a los cultivos a operaciones comerciales en la economía de mercado (CarriIlo, 2017). Por ello, aunque entre 1961 y 1968 se constituyeron más de ochocientas organizaciones cooperativas (mayoritariamente del sector agropecuario) su vida fue efímera, tanto que, como señaló Robert Flick para este periodo, las cooperativas con demasiada frecuencia mantuvieron un carácter estrictamente nominal (Da Ros, 2007: 257).
Si bien los argumentos a favor de la formación de cooperativas y otras formas colectivas de organización social del trabajo eran fundamentalmente económicos, otros fueron explicita o tácitamente hegemónicos. Por esta razón, es plausible colegir las palabras de Kay acerca de que estas formas de organización socioeconómica resultaron, paradójicamente, muy comunes en el mundo capitalista, pero también entre aquellos regímenes políticos de clara inspiración revolucionaria. ¿Por qué? Por un lado, los argumentos económicos persuadían a los reformadores de los peligros de no mantener un cierto equilibrio hacia un modelo de transición gradualista, es decir, en teoría debía evitarse la subdivisión excesiva de las propiedades heredadas del ancien régime hacendatario; en caso contrario se precipitaría el otro problema que había caracterizado a la agricultura latinoamericana, esto es, la precaria explotación minifundista. Por otro, la defensa de las virtudes de la organización colectiva contenía una buena dosis de dominación social desde arriba puesto que permitía un mayor "control gubernamental directo" sobre el sector reformado (Kay, 1998: 77-78).

Convencionalmente se asume que el sector reformado carecía de los instrumentos técnicos y administrativos, pero también de capital monetario/financiero y un adecuado marco institucional, factores que podían hacer que los pequeños productores no quedaran excluidos de la economía de mercado. Sin embargo, siendo plausible lo anterior, no es menos cierto que frecuentemente los obstáculos se hallaban dentro de la propia maquinaria del aparato estatal que no solo no alcanzaba a proporcionar aquellos servicios sino que en ocasiones los restringía. No de otra manera cabe interpretar que el Instituto Ecuatoriano de Reforma Agraria y Colonización (IERAC), organismo gubernamental gestor del proceso reformista, desmovilizara al "campesinado a través del fomento de la colonización" de tierras demográficamente vacías especialmente en la región subtropical, o garantizara "por encima de todo, la reconversión de las mejores tierras de buena parte de las antiguas haciendas andinas en unidades capitalizadas y orientadas al mercado urbano" o al pujante sector agroexportador (Bretón, 2001: 42).

En resumen, la concentración de la tierra en el país andino medida a través del clásico coeficiente de Gini tan solo disminuyó de 0,86 en 1954 a un 0,80 en el primer año del presente siglo, es decir, "las reformas agrarias no tuvieron un impacto importante en la redistribución" de la propiedad agrícola (Martínez Valle, 2014: 44). Incluso allí donde los campesinos pudieron acceder a un pedazo de tierra, la adquisición de la titularidad les llevó años cuando no décadas debido, en parte, a una onerosa burocracia estatal. Así pues, quedó manifiestamente claro que "la política gubernamental no solo tenía prejuicios contra la agricultura, sino dentro de la agricultura contra los campesinos y los trabajadores rurales" (Kay, 1998: 63-68 y 98). Como consecuencia, la modernización "desde arriba" del mundo rural desplazó forzosamente a los pobres rurales hacia las ciudades principales e intermedias del país, donde, como señala Mike Davis, "hicieron valer su derecho a la ciudad, aunque esto solamente significara un tugurio en las afueras" (Davis, 2014: 78). Pronto la asombrosa urbanización de la pobreza se mezcló indisolublemente con unas políticas de industrializa- 
ción incapaces de cubrir la espectacular demanda de empleo. La razón principal obedecía a una nueva reconstitución de la economía política: mientras la tradicional sociedad agraria iba siendo socavada por la capitalización del sector agrícola y, por tanto, por los valores de uso, el crecimiento económico se orientaba hacia una profundización de la dependencia del volátil y concentrado sector externo.

Efectivamente, durante los primeros años del decenio setenta la acumulación de capital se basó en las exportaciones de petróleo extraído del rico subsuelo de la región amazóni$\mathrm{ca}$, en medio de un contexto internacional de bonanza de los precios de los hidrocarburos. El sector externo petrolífero reactivó vigorosamente la economía: “las exportaciones se quintuplicaron holgadamente entre 1970 y 1975, mientras que el producto interior bruto creció un $14 \%$ en 1972 y más del $25 \%$ en 1973" (Salgado, 1987: 135-152). Las divisas que ingresaban en las cuentas fiscales durante el gobierno de las "dictaduras petroleras" robustecieron el papel del Estado que virtualmente controlaba el $80 \%$ de la industria petrolífera (sin omitir que hacia 1976 de una treintena de empresas, "catorce eran de propiedad de capitales transnacionales") (Ayala Mora, 2002: 284). Pronto se hicieron evidentes las consecuencias y las contradicciones de esta abrupta dependencia del sector externo. En parte, porque las políticas de Industrialización por Sustitución de Importaciones (ISI) cubrían con cierta exclusividad las demandas de las clases medias y altas de la estructura social, y en parte porque la demanda laboral del tejido industrial no alcanzaba a cubrir el aumento progresivo e imparable de la miríada de desempleados excluidos de las marginadas, o bien capitalizadas, zonas rurales que acudían en busca de trabajo. El crecimiento vegetativo que había duplicado la población entre 1950 y 1970 superando los 6,5 millones de habitantes se combinó con la vasta masa de población fugada del campo. Ambos factores provocaron que las principales ciudades del país, Quito y Guayaquil, albergaran el $42 \%$ de la población nacional para el periodo citado y, como era de prever, el interior de los territorios urbanos o sus extrarradios adquirieron una fisonomía indefinible y con frecuencia incontrolable donde la imponderable economía sumergida o el subempleo constituían las únicas alternativas para la reproducción social de los sectores sociales pobres y marginados. Aunque una parte considerable de la fuerza de trabajo inmigrante fue absorbida por el mercado inmobiliario urbano, el acceso a los inmuebles fue muy limitado para las clases populares desplazadas irremisiblemente a poblados de chabolas o barrios degradados. Sin embargo, a pesar de estos factores, o precisamente por ellos, la política y la movilización de las masas no se mantuvieron inactivas.

Durante el decenio de 1970 se consumó más nítidamente el "perfil obrero" y las reivindicaciones de las organizaciones sindicales fueron adquiriendo una cierta representación nacional (Farrell, 1985). En el campo se desarrollaron, o ampliaron, asociaciones sindicales tales como la Fe $\neg$ deración Ecuatoriana Indígena (FEI) que junto a la Confederación de Tra $\neg$ bajadores del Ecuador (CTE) habían protagonizado la gran marcha por la reforma agraria durante el III Congreso de la FEI celebrado en 1961 y diez años después, en 1972, introdujeron en la agenda política la Primera Conferencia Latinoamericana de Reforma
Agraria, respaldada por la Central Ecuatoriana de Organizaciones Clasistas (CEDOC) y la Federación Nacional de Organizaciones Campesinas (FENOC) (Carrillo, 2014: 172). Esta explosión de las movilizaciones campesinas se combinó con el auge del movimiento obrero en correspondencia con las políticas de industrialización, provocando un incremento relativo del "sector de trabajadores asalariados en todas las esferas económicas" (Paz y Miño, 2016).

Pero, aunque los partidos políticos de izquierdas sufrieron un robustecimiento orgánico durante la fase desarrollista del capitalismo de Estado, también se produjeron disensiones en su estructura interior. Así por ejemplo, la militancia del Partido Comunista comenzó a gravitar entre los partidarios del maoísmo y aquellos otros que parecían más afines a las políticas de la Unión Soviética (Ayala Mora, 2002: 279). Sin embargo, a pesar de estas escisiones típicas de las turbulencias de la Guerra Fría, por el momento los movimientos sociales y políticos de la izquierda tradicional (y esto fue, como sabemos, una tendencia marcadamente global) no gravitaban en torno a "objetivos específicos de cada grupo", al contrario, buscaban desesperadamente luchar por "grandes causas universales a través de las cuales cada grupo creía que podría llegar a ver realizados sus objetivos particulares" (Hobsbawm, 2000: 119).

Con todo, las divisiones ideológicas apuntadas no constituyeron una particularidad exclusiva de los territorios políticos de la izquierda o de los movimientos sociales de masas contrahegemónicos. Las fuerzas políticas reactivas a estos movimientos sufrieron cambios en algunos aspectos muy notables. El vetusto edificio de la Iglesia católica comenzó a transformarse, al menos una parte nada desdeñable de la curia eclesiástica, ante la fuerza expansiva de las corrientes progresistas inspiradas en la "teología de la liberación" muy ajustadas al pensamiento dependentista y a la asombrosa desigualdad continental. No por casualidad a ojos de las facciones tradicionalistas y neoconservadoras esta teología de los marginados, en palabras de Cueva, representaba una "doctrina política disfrazada como creencia religiosa" $y$, sobre todo, "contraria" al espíritu de la "libre empresa" (Cueva, 1998: 257-258).

En resumen, es evidente que la economía a secas aunque había acelerado la transformación del país andino durante el periodo desarrollista se había desvelado del todo insuficiente. Como observó Lefeber, analizando las contradicciones subyacentes de aquel periodo en el país andino:

“Las políticas estatales al promover la sustitución de trabajo por capital, la dependencia en las importaciones y préstamos externos y al privilegiar las exportaciones y el crecimiento urbano a expensas de la agricultura y del desarrollo rural y regional, han establecido, también, una estructura socioeconómica y un conjunto de relaciones político-económicas, difíciles de reencauzar en una dirección socialmente constructiva" (Lefeber, 1985: 27).

De hecho, todos estos factores eran claramente patentes al finalizar la década 1970. La diversificación económica se mantuvo congelada y el país no había superado la dependencia del sector de hidrocarburos. Al mismo tiempo que las exportaciones petrolíferas descendieron, se produjo una revitalización de la producción agrícola de cultivos tradicionales principalmente de banano, cacao y café, junto a otros cultivos no tradi- 
cionales (camarón, flores, etc.), destinados en su mayor parte al mercado internacional. El camino hacia la reprimarización económica se combinó con la disminución de los ingresos estatales y la deuda externa, cuya participación en el PIB alcanzaba un abrumador 66\% en 1983 (Fontaine, 2002: 107). Por fin el deseo irresistible a instancias de Washington de convertir a los países latinoamericanos en clientes se había consumado. Evocando a Hirschman, los "prestatarios latinoamericanos fueron cortejados por los prestamistas" y guiados por "la vía del jardín, al final de la cual se les administró el "choque Volcker" de las tasas de interés rápidamente crecientes" (Hirschman, 1987: 799$803)^{5}$. La crisis de la deuda externa junto a las contradicciones generadas por la fase desarrollista del capitalismo de Estado, se combinaron dramáticamente, tal como analizaremos, con la nueva era de las políticas de ajuste estructural neoliberales, socavando de este modo las expectativas de una economía política menos reacia a distribuir la riqueza del país.

Como pronto quedó constatado la construcción de una economía social a través de la organización del trabajo en forma de cooperativas se hallaba orgánicamente entrelazada a esta asfixiante economía política. Así, entre 1979 y 1983 se habían registrado en el país la formación de más de 11.000 organizaciones de las cuales únicamente el 9,1\% se declaraban dentro del ámbito del sector cooperativo, el resto estaba formado por un ambiguo conjunto social de "centros de alfabetización y organizaciones de desarrollo comunales" (Da Ros, 2007: 266). Tal como expondré a continuación, durante las fatídicas décadas de las reformas neoliberales, la economía social y las organizaciones que decían estar dentro de este impreciso campo se decuplicaron, llegando a ser calificado dicho fenómeno asociativo como una auténtica "revolución". Sin embargo, las ideas que subyacían entre los valedores de esta nueva "revolución asociativa"6 guardaban frecuentemente estrecha semejanza con la crítica que Engels, en uno de los prefacios al Manifiesto comunista, había lanzado contra las sectas que como corrientes alternativas al agonizante socialismo utópico deseaban, con sus "variadas panaceas y emplastos de toda suerte", suprimir las miserias sociales "sin dañar en lo más mínimo al capital y a la ganancia" (Marx y Engels, 2011: 94).

Neoliberalismo y"revolución asociativa"

Con las doctrinas neoliberales el capitalismo de Estado entró en su fase crepuscular. Había comenzado, en palabras

\footnotetext{
5 Las consecuencias también se notaron en Estados Unidos, como afirma Streeck, cuando "Paul Volcker, recién nombrado presidente del Banco de la Reserva Federal de EEUU por el presidente Carter, elevó los tipos de interés a alturas sin precedentes", provocando que las tasas de desempleo se elevaran a "niveles nunca vistos desde la Gran Depresión". Wolfgang Streeck (2011).

${ }^{6}$ La idea fue introducida por Lester M. Salamon a mediados de los años noventa. Para este autor las consecuencias de la espectacular explosión de voluntarismo y mancomunidad social que él creía ver a nivel global constituía un acontecimiento histórico de tal envergadura que podía equipararse con el contexto en el que surgieron los Estados-nación. En sus propios términos: "Indeed, we are in the midst of a global "associational Revolution" that may prove to be as significant to the latter twentieth century as the rise of the nation-state was to the latter nineteenth". Véase Salamon (1994: 109-122). Una discusión más extensa en Bretón (2001)
}

de Ocampo, "el episodio económico más traumático que ha experimentado América Latina a lo largo de su historia" (Ocampo, 2014: 19-51). Un largo "camino de servidumbre por deudas, deflación y austeridad" (Hudson, 2010) guiado por la programática prescriptiva de la racionalización capitalista del denominado "Consenso de Washington". Las dramáticas consecuencias sociales de estas políticas fueron distribuidas generosamente entre los sectores sociales más desfavorecidos de Ecuador. Consecuencias que pronto se pudieron observar entre las áreas depauperadas de las ciudades, principalmente en Quito y Guayaquil, aunque no exclusivamente, donde desde las décadas del periodo desarrollista, tal como expusimos, se había ido asentando un abrumador contingente humano migrado desde un mundo rural maltratado por un insignificante reparto agrario y un espectacular racismo.

En la periferia urbana o fuera de las fortalezas gentrificadas, carentes de cualquier servicio público y de unas condiciones de salubridad básicas, las poblaciones expulsadas del campo buscaban un asentamiento donde poder subsistir. Con cierta regularidad y siguiendo la normativa jurídica se organizaban en exiguas formas pre-cooperativas con el único fin de "legitimar su situación" de inmigrantes en proceso de reasentamiento ante las autoridades locales (Da Ros, 2007: 268). El resultado fue la construcción de un urbanismo hiperdegradado que se combinó con las políticas antisociales del monetarismo neoliberal, exacerbando la pobreza en "zonas urbanas de la Sierra y de la Costa" en un abrumador 80\% entre 1995 y 2001. Durante ese mismo periodo el espectro de la desigualdad se extendió amplia y profundamente por todo el país, pasando de 3,5 millones de pobres a la dramática cifra de 5,2 de una población total que sobrepasaba ligeramente los 12 millones. Tan solo en ciertas zonas rurales de la región del litoral la pobreza se mantuvo "constante" (World Bank, 2004: Vl; Acosta, 2005). Pero la sobrecarga humana en espacios urbanos insalubres desprovistos de instalaciones públicas pronto atrajo a la pesadilla de la contaminación. Las dos ciudades mencionadas, a mediados de los años ochenta, producían en conjunto el 33\% de las 5.000 toneladas diarias de desechos sólidos expulsados con regularidad a cielo abierto (los vertederos controlados eran escasísimos). Pronto las deletéreas condiciones ambientales pusieron de manifiesto lo que, paradójicamente, no era tan evidente para la estricta división del trabajo académico: que la ciudad y el campo se hallaban estrechamente vinculados no solo por factores productivos o económicos, sociales y políticos, sino también por los desechos y los implacables insecticidas y otros insumos químicos que circulaban libremente por los ríos y la dieta alimentaria (Landázur y Jijón, 1988: 53 y 71).

En otras palabras, las "condiciones de vida y de trabajo de las capas medias, trabajadores y sectores populares" se agravaron escandalosamente, al mismo tiempo que el fetichismo de mercado elevó la concentración de la riqueza hacia la cúspide de una minoritaria clase social (Paz y Miño, 2016: 16). Si en 1990 el $20 \%$ de los sectores más empobrecidos apenas percibía el $4,6 \%$ de los ingresos, al finalizar dicha década su participación en la distribución se había reducido a un minúsculo 2,5\%; por el contrario, los segmentos sociales elitarios ascendían por la escalera de la acumulación de riqueza pasando de un $20 \%$ a un escandaloso $60 \%$ de la renta nacional (Acosta, 2005). ¿Bajo 
qué condiciones económicas y políticas se produjo esta regresión social en Ecuador?

Las turbulencias de la crisis económica en los países emergentes de Asia Oriental hacia 1997, que pronto se extendieron por la región dando lugar al ominoso "sexenio perdido" entre 1998 y 2003 (Ocampo, 2014: 19), se combinaron con la quiebra del sistema financiero en Ecuador al finalizar el siglo XX. La salida de la crisis obtuvo la típica respuesta neoliberal consistente en aplicar programas de rescate del sector bancario, operación que absorbió en torno al $23 \%$ del PIB (Cotler, 2005), a la vez que el gasto público era deprimido severamente. Adicionalmente se introdujo una nueva contradicción en la economía política que venía a ampliar la brecha de la autonomía monetaria del país: la dolarización. Como señaló sagazmente Max Weber, dado que el control del dinero es el producto de "conflictos de intereses y de compromisos como resultado de las constelaciones del poder" (Weber, 1978: 107-108), la adopción del dólar estadounidense restringió considerablemente la acción política gubernamental, generando un campo de tensiones políticas que confinaron las expectativas de cambios estructurales a los imperativos del reino del mercado global. Si bien desde la perspectiva de la economía estándar la dolarización debía proporcionar un entorno económico estable, limitando teóricamente las contingencias de la hiperinflación y "el riesgo de endeudamiento externo", la pérdida de autonomía monetaria, por el contrario, contribuyó a circundar la "capacidad política" del ejecutivo en la toma de decisiones relativas a "políticas macroeconómicas anticíclicas", lo que contribuyó a agravar los ciclos de auge y recesión (Clark y North, 2018).

Las estrictas condiciones del contexto político de ajuste estructural debilitaron a las organizaciones sindicales. La austeridad fiscal y la flexibilidad del mercado laboral produjeron una progresiva pero imparable precarización del trabajo, pero también un continuo proceso de desindustrialización junto a la privatización de los activos estatales. De hecho, durante los primeros años del presente siglo el sector manufacturero solo aportaba un $20 \%$ de la demanda laboral, mientras el sector terciario absorbía a más del $70 \% 7$. Seguramente el epítome más dramático de las políticas ultraliberales fue el espectacular movimiento de emigrantes expulsados fuera de las fronteras del país que alcanzó durante los primeros años del siglo XXI a algo más del $12 \%$ de la población ecuatoriana. Las remesas que enviaban desde el extranjero estos hombres y mujeres no solo contribuían al sostenimiento de sus familias (Jokisch y Kyle, 2005: 57-69), también, y paradójicamente, constituían la segunda fuente de divisas para la financiación de la economía nacional, únicamente superada por el sector petrolífero ${ }^{8}$. Pero las forzadas migraciones también trastocaron las bases de las estructuras sociales especialmente entre las comunidades rurales. La división del trabajo compartida tradicionalmente por hombres y mujeres tuvo que ser soportada exclusivamente

\footnotetext{
${ }^{7}$ Informe de desarrollo social 2006: Mercado laboral ecuatoriano. Análisis 1990-2005. Secretaría Técnica del Ministerio de Desarrollo Social, Quito, 2006, pp. 38, 53 y 67.

8 Frecuentemente los recursos monetarios derivados de las remesas acababan en manos de los prestamistas legales o ilegales que sufragaron la emigración o de las "empresas que han asumido el negocio de las transferencias". Véase Acosta (2005: 4 y 26); para un examen minucioso y estructural sobre los flujos migratorios EcuadorEspaña, véase García Martínez (2019)
}

por ellas allí donde los varones se vieron arrastrados a emigrar (Sánchez-Parga, 2006: 89). He aquí "la variable secreta y culpable de las ecuaciones neoclásicas del ajuste económico", recalca incisivamente Davis, "se espera que las mujeres pobres y sus niños carguen sobre sus espaldas con el peso de la deuda" (Davis, 2014: 204).

De forma inevitable se produjo una explosión del crecimiento del sector de la economía informal, en parte debido a la insuficiente demanda efectiva del "sector moderno", y en parte por la pobreza mencionada que se fue combinando con una fuerte debilidad institucional, o más preciso, una institucionalidad dirigida a favorecer los intereses particulares de los grupos sociales hegemónicos. Al finalizar el decenio 1990 más del $40 \%$ de la población ecuatoriana virtualmente activa se hallaba dentro de los márgenes del sector informal de la economía; un sector "desprotegido, inestable y donde los derechos de los trabajadores no son ejercidos". La típica imagen de un "ejército de vendedores que ofrecen las mercaderías y los servicios más variados" tan característica del urbanismo gentrificado se fue recrudeciendo en las principales ciudades del país ${ }^{9}$, al mismo tiempo que el mundo rural adquiría una fisonomía socioeconómica típicamente proletarizada. Pero, frente a las políticas antisociales del capitalismo neoliberal se había erigido desde principios de la década 1980 un importante contingente del "sector popular de la sociedad civil", formado especialmente por organizaciones enraizadas en la comunidad y en movimientos sociales de pobres urbanos, mujeres y comunidades indígenas (Petras y Veltmeyer, 1995: 164-179; Veltmeyer, 2008: 324).

De entre los movimientos contrahegemónicos que adquirieron mayor representatividad subversiva destacó el Frente Unitario de Trabajadores (FUT) aglutinado por diversos sectores de corte socialista que "pasó a ser la vanguardia de las resistencias y luchas sociales contra el avance del modelo empresarial-neoliberal". Sin embargo, esta situación esperanzadora comenzó a debilitarse durante el siguiente decenio. Junto a los citados factores que alteraron el desarrollo de la economía nacional, el auge del capitalismo global y la implosión de la Unión Soviética, y con ello el derrumbamiento de alternativas a modelos de desarrollo diferentes al Occidental, actuaron corrosivamente contra la "época heroica de las luchas y las huelgas nacionales" que "rápidamente quedó en el pasado" (Paz y Miño, 2016: 16-17). De hecho, la fuerza de la organización sindical que en su máximo auge había alcanzado el 15\% de la población trabajadora fue reducida durante las políticas neoconservadoras por debajo del 5\% (Ospina Peralta, 2011: 108).

Por un tiempo el vacío sindical de los años noventa fue ocupado, en cierto modo, por el que fue considerado uno de los movimientos políticos de organizaciones indígenas más potente de América Latina. El terremoto que desencadenó dicha movilización social de indios, especialmente durante los levantamientos de 1990 y 1994, transformó el movimiento de protesta en una conquista de representación de la esfera política. Las comunidades o, más preciso, sus representantes podían ahora actuar como correctivo democrático especial-

\footnotetext{
${ }^{9}$ Informe de desarrollo social 2006: Mercado laboral ecuatoriano... cit., p. 54. Véase también Cevallos (1999)
} 
mente allí donde las políticas eran reacias a considerar los derechos de ciudadanía de los sectores sociales que secularmente habían sido marginados (León Trujillo, 2010). En la perspicaz interpretación de Sánchez-Parga, esta explosión sociopolítica hundía sus raíces en el largo camino recorrido entre la citada Ley de Comunas de 1937 -cuando se inicia el "reconocimiento jurídico" de la comunidad indígena en Ecuador que supuso al mismo tiempo "una toma de conciencia de la dimensión comunal de la sociedad indígena" junto al fortalecimiento de la "cohesión social de los grupos indígenas andinos"-, y su consecuencia política: la representación orgánica de la sociedad indígena en las instituciones del Estado a través del partido político Pachakutik en 1996 (Sánchez-Parga, 2009: 18-19). Sin embargo, como ya advirtió Gramsci, "una cosa es la democracia de partido y otra la democracia en el Estado" (Gramsci, 1981: 272). Las fuerzas de resistencia populares que habían luchado contra las políticas gubernamentales y de mercado antisociales, depositando sus esperanzas en ejecutivos que decían escuchar los ecos del chavismo y prometían implementar políticas "nacionalistas-populares", como fue el caso del coronel Lucio Gutiérrez (2003-2005), pronto se vieron subvertidas por las recomendaciones del FMI y su espíritu neoliberal cimentado en la privatización de la esfera pública. Pero también por las cesuras que se iban abriendo en el interior de las mismas organizaciones sociales del movimiento indígena, acosadas y seducidas por programas cortoplacistas y frecuentemente tecnocráticos inspirados y amortizados por las instituciones financieras globales ${ }^{10}$.

De hecho, lo cierto es que las políticas de desarrollo que se extendieron de manera espectacular sobre el mundo rural excluyeron sistemáticamente de las agendas gubernamentales la cuestión central e irresuelta, y sin duda agravada, de la "concentración de la riqueza" (Bretón y Martínez Novo, 2015: 29). La secular cuestión agraria que había permanecido vinculada de forma inexorable al "problema del indio" desde el lúcido pensamiento marxista de Mariátegui se disolvió en el nuevo "escenario posreformista" (Bretón, 2017: 150). Bajo este contexto abiertamente hostil a cualquier alternativa social que actuara como contratendencia a la implacable ley de hierro del mercado autorregulado, la mera organización no implicaba necesariamente un cambio en las abyectas condiciones sociales de los pobres y excluidos. Seguramente la causa principal, como había señalado el informe de Naciones Unidas The Challenge of the Slums, "fue el retraimiento del Estado" como imperativo de las políticas de ajuste estructural que incentivaron la liberalización de los mercados y la privatización de empresas estatales.

El vacío de gobernabilidad al que fueron sometidos los estados, traducido de forma inminente en una disminución abrumadora de la capacidad de acción política, fue llenado por un espectacular "traspaso de competencias a escalones más bajos de gobierno y en especial a las Organizaciones No Gubernamentales (ONG), vinculadas frecuentemente a los principales organismos de ayuda internacional"11. Pero la cues-

\footnotetext{
10 Un caso representativo fue el Proyecto de Desarrollo de los Pueblos Indígenas y Negros del Ecuador (PRODEPINE) implementado por el Banco Mundial.

${ }^{11}$ Véase UN-HABITAT, The challenge of the Slums: Global Report on Human Settle-
}

tión principal del vacío de poder estatal enmascaraba, de hecho, los anhelos neoliberales de socavar las bases de la política pública. Ahora, el capital liderado por los utópicos neoliberales podía realizar sus operaciones especulativas y rentistas eludiendo sistemáticamente las indeseables injerencias políticas en sus intereses particulares, al mismo tiempo que se servía de toda una estructura institucional, ambiguamente antiestatista, que vinculaba directamente las instituciones financieras globales con las propias comunidades locales a través de un ejército de intermediaros y agencias onegeístas. "Este sistema escalonado de coordinación y financiación", como incisivamente colige Davis, pronto fue bendecido por políticos e intelectuales pertenecientes a un amplio espectro ideológico con conceptos deliberadamente imprecisos como, por ejemplo, "capacitación", "sinergia" y "gobierno participativo" (Davis, 2014). A finales del decenio de 1990, al mismo tiempo que proliferaban estas nuevas narrativas analgésicas convincentemente abonadas por expertos funcionalistas y por la izquierda neoliberal, la corrosiva pobreza en el país se combinaba con asignaciones a la deuda externa de más del $20 \%$ de los ingresos provenientes de las exportaciones (Petras y Veltmeyer,1995: 177). Paradójicamente, en este breve lapso de tiempo prosperaron en Ecuador más del $70 \%$ de todas las ONG que lo hicieron a lo largo del siglo XX (Bretón, 2001: 240). En cierto modo, esta es una consecuencia, entre otras, de la parálisis a la que se ven abocados aquellos estudios que trazan una virtual separación entre el mundo de las ideas o de la cultura y la economía. ¡No basta con estar capacitados o con proclamar de forma ingenua neologismos para hacer que mejoren las condiciones de vida de hombres y mujeres!

En cierto modo, aquellas organizaciones civiles y autodenominadas no gubernamentales que habían sido especialmente agresivas con "los recortes del gasto social público" y en general con la "privatización de las políticas sociales", se convirtieron en los principales organismos canalizadores de las políticas de "compensación social" dirigidas por las instituciones financieras globales (BM, FMI, etc.). Un "complejo caritativo-industrial" (Harvey, 2014: 277) que sin duda ha sido tan heteróclito en su composición social como en los apremiantes problemas que pretende resolver (género, medioambiente, migraciones, etcétera). Esta nueva corriente mundial abonada por amplios sectores políticos y sociales de izquierdas demostraba estar afectada por dos problemas orgánicamente entrelazados. El primero, como ya indicó Hobsbawm, aunque las reivindicaciones apuntadas podían ser no solo legítimas sino irrevocables, "conquistar mayorías no equivale a sumar minorías" (Hobsbawm, 2000: 121). Segundo, las organizaciones de munificencia frecuentemente compartían un factor en común, a saber, nunca o casi nunca eran abiertamente "anticapitalistas" y aunque decían defender ideas "progresistas", de forma tácita o normativa se inclinaban con menos objeciones de las esperadas hacia políticas deliberadamente neoliberales, tal vez porque su propia existencia se hallaba legitimada y justificada por "la privatización de las funciones del Estado". ¿No constituyó, acaso, la expansión de la economía financiera a tra-

ments 2003, Londres, 2003. Citado en Mike Davis (2004). 
vés de microcréditos el instrumento económico, aplicado por amplios sectores del espectro político y financiero, para que las clases sociales marginadas pudieran finalmente alcanzar las virtudes de la utopía neoliberal? No fue casual que durante los primeros años del siglo XXI un abrumador 75\% de organizaciones cooperativas en Ecuador estuviera inscrito dentro del sector financiero y solo un minúsculo $1,6 \%$ se hallara dentro del productivo. Seguramente es poco objetable afirmar que la cara más amarga de esta apología financiera no ha dejado de ser la microexplotación tras un "alivio transitorio" de unos problemas extensamente estructurales (Harvey, 2016: 209; Coraggio, 2016).

De este modo, el centro de gravedad de la acción política del Estado, de acuerdo con Bretón, se desplazó hacia nuevos agentes del "desarrollo" que comenzaron a extenderse principalmente por los heterogéneos territorios rurales del país. Al mismo tiempo que se ensalzaban los vínculos comunitarios y asociativos, acreditados convincentemente, en palabras de North, por "el espíritu emprendedor de la gente pobre", se cerraban las alternativas estructurales, limitadas ahora al esencialismo definitivamente ecuménico de la "iniciativa empresarial" (Bretón, 2001: 238-239; North y Cameron, 2008: 16-19). La convergencia ideológica entre los apóstoles de la economía estándar y amplios sectores sociales e intelectuales que ingenua o deliberadamente decían situarse contra los primeros, no fue capaz de corregir la pobreza o de generar una economía de rostro más social. De hecho, aunque constituyen excepcionalidades, allí donde hubo distribución de activos naturales durante el tímido ciclo reformista inducido por el desarrollismo, o donde no se objetó el apoyo técnico y financiero a los pequeños productores, la dependencia de la munificencia privada o estatal fue minúscula, o al menos los programas de desarrollo conseguían elevar los niveles de vida de las poblaciones rurales. Así fue colegido durante toda la década noventa en la que estuvo activo el ambicioso Programa Nacional de Desarrollo Rural (PRONADER), cuya financiación procedía principalmente de préstamos del Banco Mundial. El impacto positivo de dicho programa entre los arroceros de la cuenca del bajo Guayas no fue fortuito, sino consecuencia de la reforma agraria de los años setenta. Aunque también desveló que la corrupción estatal, la manipulación de los proyectos por parte de los intereses terratenientes y las tensiones competitivas entre ONG restringieron severamente las oportunidades y la viabilidad económica y social de estos programas (Martínez Valle, 2008: 125).

Otra excepcionalidad se situaba en la provincia de Tungurahua, donde desde los años veinte del siglo pasado hubo un mercado de tierras relativamente igualitario y el huasipungo, la versión ecuatoriana de la servidumbre indígena, fue prácticamente inexistente. Particularmente en el cantón Pelileo, pequeños artesanos combinaron la actividad textil con la explotación minifundista agrícola, suministrando su producción excedente a las dinámicas ferias locales. Una tendencia socioeconómica que apenas fue alterada durante todo el siglo XX. Solo cuando el país recusó la moneda nacional y adoptó la dolarización, la competencia feroz de productos importados afectó severamente a aquella vigorosa industria (North, 2008: 255-276). Pero en términos generales los ejemplos señalados, entre otros, no constituyeron más que singularidades a favor de políticas de corte distributivo, y puesto que éstas fueron vagamente consistentes en el país andino, la realidad estructural de los trabajadores, sindicatos y cooperativas era bien diferente.

En términos generales, durante la primera década del siglo XXI la desigualdad en el mundo rural continuaba drenando la riqueza hacia los sectores elitarios de la estructura social. Y sin embargo, como incisivamente colige Martínez Valle, la mayor parte de analistas del mundo rural ecuatoriano, tal vez demasiado desplazados hacia la "problemática indígena" -seguramente porque ésta se hizo dramáticamente visible en las ciudades de la Sierra donde la "casi totalidad de los mendigos estaba formada por población eminentemente indígena" (Sánchez-Parga, 1996)-, no siempre visibilizaron "otras situaciones de pobreza iguales o más agudas que se desarrollaban en los islotes de modernidad empresarial de la sociedad rural". Hombres y mujeres del campo, proletarizados y vinculados al trabajo asalariado "en condiciones de extrema precariedad e inseguridad con un mercado laboral flexible y desregulado", apenas cubrían las necesidades alimentarias básicas. La formidable dimensión que fue adquiriendo este ejército permanente de reserva de mano de obra hacía que las luchas de los trabajadores rurales quedaran paralizadas ante la "amenaza de despido", especialmente allí donde las infames condiciones interpelaban el deseo de organizarse para combatirlas. Paradójicamente, estas condiciones inhumanas de trabajo se volvieron con asombrosa frecuencia "invisibles" para los gobiernos de turno, "las ONG y hasta para las mismas organizaciones sociales" (Martínez Valle, 2007: 209-219).

En síntesis, la "revolución asociativa" que se produjo dentro del marco de las políticas de ajuste estructural no respondía a la lógica tradicional de las organizaciones sociales populares. Pero tampoco el tradicional cooperativismo pudo actuar como catalizador social con el fin de evitar las clásicas tensiones entre capital-trabajo. De hecho, las contradicciones de un capitalismo que provocaba permanentes fracturas sociales se iban multiplicando, quedando orgánicamente entrelazadas. Las políticas de desarrollo social acabaron dominadas por la lógica asistencialista o compensatoria inscrita en las instituciones internacionales y en la mecánica de la burocracia estatal instrumentalizada por aquéllas y por las élites reacias a subvertir dichas condiciones sobre las que basaba el usufructo de sus rentas crecientes. El Estado, afirma Abrams, es un "mito que convierte lo abstracto en concreto" (Abrams, 1988: 69), por ello Panitch y Konings inciden en que la neoliberalización no puede reducirse a una interpretación, tal vez demasiado simplista, de "retirada institucional", más bien conllevó la "expansión y consolidación de las redes de vínculos institucionales que sostenían el poder imperial de las finanzas estadounidenses" (Panitch and Konings, 2009: 67-83). ¿No fueron acaso las agencias internacionales (FMI, BM, etc.) las que operaban a través de las instituciones públicas del aparato estatal y/o de las concesiones hechas por ellas a toda una estructura de organizaciones privadas? Mientras el aparato internacional de donaciones funcionalistas operaba sobre amplias capas sociales escarbando su espíritu empresarial, el paradigma del Estado social, encauzado a salvaguardar y equiparar "el acceso y las oportu- 
nidades, con independencia del nivel de ingresos y del estatus social", quedaba socavado por los inestables y abiertamente excluyentes mecanismos de mercado (Lavinas, 2014: 48).

De hecho, la política pública enconadamente neoliberal, temiendo que la pobreza se transformara en una indeseada subversión social, puso en circulación al finalizar la década noventa el denominado "bono solidario". Estos "programas de transferencias condicionadas", tal como fueron conocidos a nivel continental, no solo legitimaban el inmovilismo de los funestos rasgos estructurales de la desigualdad, también, como afirma Burchardt, actuaron con cierta disposición paternalista al condicionar las "prestaciones educativas y sanitarias básicas" a cambio de una "adecuada" conducta política por parte de los electores que dependían de estos donativos institucionales (Burchardt, 2017: 346-347). Pero, incluso, cuando se produjo el fortalecimiento de la política pública, "el regreso del Estado" en consonancia con "el giro a la izquierda" de gran parte de los países de la región-, muchas de las contradicciones apuntadas siguieron actuando en Ecuador contra el fortalecimiento de las bases de una economía de rostro social. No obstante, parecía que las fuerzas irrestrictas del libre mercado se hallaban de nuevo contenidas por la política del Estado planificador.

Neodesarrollismo y "revolución ciudadana"

Efectivamente, durante los primeros años del siglo XXI se produjeron en buena parte de las repúblicas de América Latina toda una serie de acontecimientos políticos que marcaron, en palabras de Löwy, "un Ilamativo contraste con la mayor parte del resto del globo. Gobiernos de tendencias izquierdistas, a menudo respaldados por movimientos populares radicales" (Löwy, 2011: 123-131), intentaron confrontar la ideología neoliberal que, como cáusticamente afirma Palma, había conquistado la región después de 1980, "incluida la mayoría de sus intelectuales progresistas, tan completamente (y tan ferozmente) como la Santa Inquisición conquistó España" (Palma, 2014: 2). Los prefijos fueron la forma gramatical más común para delimitar la que era concebida como una nueva fase histórica en la región, aunque precisamente su uso denotara con frecuencia la incomprensión de los acontecimientos o, tal vez, el manifiesto anhelo de cambiar la amarga situación de amplias clases sociales excluidas de las promesas de la "doctrina de la economía de goteo de Ayn Rand y Frederick Hayek" (Hudson, 2018: 386). Palabras como neodesarrollismo, posneoliberalismo, poscapitalismo, inter alia, penetraron insistentemente en el patrimonio intelectual y en la retórica política de la izquierda ${ }^{12}$. Probablemente el acontecimiento más llamativo de este nuevo ciclo político, o al menos el que más

\footnotetext{
12 Seguramente, y de acuerdo con Hobsbawm refiriéndose a la revolución social de la segunda posguerra en Occidente, "estos prefijos indicaban el reconocimiento oficial de una defunción, sin implicar consenso o certeza alguna acerca de la naturaleza de la vida después de la muerte". Véase Hobsbawm, (1995: 290-291).
}

difusión tuvo a nivel internacional, después del chavismo, fue la irrupción del programa político de la "revolución ciudadana" liderada por el presidente Rafael Correa (2007-2017) y su partido político Alianza País (partido inspirado en el ambiguo "socialismo del siglo XXI", concepto originariamente atribuido al sociólogo alemán Heinz Dieterich ${ }^{13}$ y puesto en circulación global por la "revolución bolivariana" de Hugo Chávez).

La praxis política del Gobierno correísta, sin embargo, pronto comenzó a despertar suspicacias (aunque también devociones), especialmente cuando en 2008 el ejecutivo decidió incluir en la Carta Magna -un año después lo haría el gobierno boliviano del indio aymara Evo Morales- una mezcolanza de "cosmovisiones indígenas" y principios éticos como frentes de batalla conceptuales para desterrar no solo los presuntos restos del pasado neoliberal, sino también con toda la larga tradición del pensamiento liberal que según sus críticos adolecía de un sesgo marcadamente eurocéntrico (Bretón, 2013: 72). Empero, como pronto quedaría demostrado, la brecha existente entre la realidad socioeconómica ecuatoriana y las expectativas de la notable retórica política se iba a mostrar infranqueable. De hecho, para empezar, la reconstrucción esencialista del pasado indígena mantenía cierta afinidad con la crítica del fecundo pensamiento de Maquiavelo contra los estadistas que afanosamente ocupados en "cómo deberían ser las cosas" descuidan el problema principal, a saber, "cómo las cosas son"14. Precisamente por ello, la resignificación del relato indígena deba ser interpretada de forma más congruente como una ambigua respuesta del malestar colectivo provocado por las contradicciones que han mantenido activas las tensiones del dominio de un capitalismo rentista, frecuentemente autoritario, y la desesperada búsqueda de una política democrática en el país andino.

¿Debemos entonces inferir a la luz de la reflexión anterior que el programa político de la "revolución ciudadana" se mantuvo ajeno a la compleja realidad económica y social del país, tan característica, por otro lado, de espacios nacionales inestables "en sus relaciones sociales internas" y en permanente búsqueda de nuevos mercados, materias primas y oportunidades de inversión? (Davidson, 2013: 889). Al menos desde la oratoria política del ejecutivo y el raudal ilimitado de informes institucionales no faltaron argumentos a favor de una diversificación de la economía, introduciendo, además, cambios en los sistemas productivos y extractivos con el fin de que fueran ecológicamente sostenibles, así como una adecuada corrección política más prolífica a distribuir la riqueza económica del país entre los sectores sociales marginados. Habida cuenta de la fuerte dependencia de la economía monoexportadora se apeló tácitamente a la tesis Prebisch con la añadidura citada de la adulteración del pasado indígena. Desde esta perspectiva gubernamental se debía de forma irrevocable transformar el "patrón de especialización de la economía a través de la sustitución selectiva de importaciones para el Buen Vivir"15. (Sin-

\footnotetext{
13 Véase, por ejemplo, Dieterich (2006).

${ }^{14}$ La crítica más audaz dirigida a este esencialismo puede hallarse en Sánchez-Parga (2011). La idea de Maquiavelo en Hirschman (1984: 366-367).

15 SENPLADES, "Transformación de la Matriz Productiva Revolución productiva a través del conocimiento y el talento humano", Secretaria Nacional de Planificación
} 
tagma éste último enarbolado como un auténtico manifiesto político o, más preciso, como mantra fetiche expresado frecuentemente en lengua amerindia quechua, es decir, Sumak kawsay). Como suscribió razonablemente el propio presidente Correa (también economista): "debemos hacer lo que los países desarrollados hicieron cuando se encontraban en nuestro nivel de desarrollo, y no lo que hacen ahora, cuando son los campeones mundiales en tecnología y competitividad" (Correa, 2009). Una argumentación, sin duda, corrosiva contra el mainstream del pensamiento neoclásico que Anwar Shaikh en Globalization and the Myths of Free Trade ha recalcado sin perífrasis economicistas: "casi todas las experiencias exitosas de crecimiento orientado a las exportaciones, han sido el resultado de un comercio selectivo y de políticas de industrialización". Allí donde surgían países con economías florecientes, la planificación política corregía la discrecionalidad del mercado y solo se defendía el libre comercio cuando éste ofrecía "ventajas comparativas". Evidencias que pueden ser verificadas "no solo en los últimos tiempos sino incluso en el pasado", cuando las economías avanzadas del núcleo central del capitalismo se hallaban inmersas "escalando la escalera del éxito" (Shaikh, 2007: 50-68). Parecía, pues, que las innovaciones políticas anunciadas por el ejecutivo ecuatoriano respondían a una combinación de estructuralismo, ejemplificado en la acción política del fortalecimiento del aparato estatal (neodesarrollismo), combinado con una propuesta económica más sólida y diversificada. Pero también se podían escuchar los ecos del pensamiento radical dependentista instrumentalizado en el liderazgo del presidente Correa y su semántica frecuentemente antiimperialista.

Sin embargo, aunque se produjeron mejoras claramente sustanciales en términos de infraestructura, de expansión de las políticas sociales e incluso de una relativa reducción de la pobreza, las bases materiales sobre las que se cimentó el nuevo periodo político, tras el penetrante neoliberalismo, se fundamentaron en un nuevo auge de los precios del petróleo y otros recursos naturales, es decir, en la vulnerabilidad de una política procíclica "nítidamente neo-extractivista" (Burchardt et al., 2016: 9). ¿Cómo debería interpretarse este inmovilismo del ejecutivo ecuatoriano incapaz de corregir un entorno económico primario tan característico, por otro lado, de países donde los recursos naturales abundan generosamente?

Una respuesta tan frecuente como sospechosamente ideológica ha estado liderada por la "brigada de la maldición de los recursos naturales" (Palma, 2014: 31-32). Sospechas que pueden confirmarse al observar las sugerencias políticas de dos preclaros representantes de esta corriente, Sachs y Warner. Autores que tras "descubrir" la existencia de una correlación "inversa entre la intensidad de los recursos naturales y el crecimiento económico", siguiendo la estela neoconservadora y abonando al mismo tiempo la "leyenda negra" acerca del periodo de industrialización regulado por el aparato estatal (Ocampo, 2013: 17), no dudaron en calificar de "gran error histórico" la "hipótesis Prebisch" (1950). Hipótesis que, como vimos, trataba de corregir el modelo de desarrollo volátil y de-

y Desarrollo, Quito, 2012 pendiente que caracteriza a las economías excesivamente especializadas en la producción de un número reducido de materias primas. Para Sachs y Warner, aunque la "política importa" (que ellos verifican a través de una soteriología econométrica), ésta no debía interferir en los mecanismos de mercado autorregulado y en las virtudes del "comercio abierto" (Sachs y Warner, 1997: 8, 26-28). No es casual, por tanto, que Deepak Nayyar califique a estos autores como ejemplos representativos de la apología de la globalización como único "camino de salvación" (Nayyar, 2007: 76-82). De esta manera es plausible colegir que en Ecuador, y por extensión en gran parte de América Latina, de acuerdo con Palma, los "grados de libertad" y de voluntad políticas para generar alternativas a rentas no manufactureras han quedado socavados por una combinación de ideología y de orden institucional global (Palma, 2005: 108-109).

No otra ha sido la realidad socioeconómica y política subyacentes en el país andino. Desde 1972 "la canasta de bienes exportables" apenas ha sido alterada, reduciéndose a un puñado de bienes primarios liderados por el petróleo, seguido por el pujante y concentrado mercado costeño de banano, productos de la acuicultura, café, cacao y flores, que en conjunto concentraban al escribir esto algo más del $80 \%$ del valor exportado (Larrea, 2016: 134). Factor mucho más acusado cuando la economía entró en una nueva fase de acumulación de capital durante la primera década del siglo XXI, dictada por el abrumador crecimiento económico de China y su impresionante demanda efectiva de productos primarios que provocó que los precios de estos reaccionaran positivamente. Actuando contra las expectativas del programa de la "revolución ciudadana" la economía no se orientó en la dirección opuesta del sector externo.

Y no solo eso, contraviniendo los legítimos objetivos políticos de la Administración correísta, un selecto grupo de la estructura social se estaba lucrando ampliamente de este mercado primario. Como si de un mandato imperativo se tratase: "You've really got to hand it to the Latin American capitalist elite" (Palma, 2014: 24). Más prosaicamente, mientras los empresarios ecuatorianos exportaban materias primas y productos agrícolas incrementando escandalosamente su tasa de ganancia personal, así como los salarios de sus gerentes crecían hasta sesenta veces más que el salario básico de sus conciudadanos y los beneficios de las"300 empresas privadas más grandes del país" alcanzaban el 57\% del PIB en 2013 (Ospina Peralta, 2015: 7), las competitivas empresas chinas dirigían al mercado ecuatoriano productos manufacturados de alto valor agregado ${ }^{16}$. El paradigma hegemónico del Consenso de Washington, fertilizado por el monetarismo neoliberal y la ofensiva de la derecha mundial fue cediendo paso al nuevo "Consenso de Beijing" (Slipak, 2014) que no solo elevó al gigante asiático al estatus de socio comercial, por supuesto desproporcionadamente superior, también se convirtió en el mayor acreedor económico del país una vez rebasado el umbral de la primera década del siglo XXI (Fontana, 2017; Terán, 2014). Este desequilibrio en la

\footnotetext{
16 Informe del Ministerio de Industrias y Productividad. Documento disponible en: http://www.inteligenciaproductiva.gob.ec/archivos/informes_de_economia_internacional/informe_economia_internacional_ecuador_china.pdf Con respecto a la desigualdad salarial, véase: https://www.eltelegrafo.com.ec/.
} 
balanza comercial agravó la conflictividad social, exacerbó las protestas ecológicas y minó severamente las vías alternativas hacia una economía más social y ecológicamente sostenible.

De esta manera, Ecuador parecía haber quedado atrapado en las palabras enunciadas en 1972 por el expresidente ecuatoriano Galo Plaza (1948-1952) que, en calidad de secretario general de la Organización de Estados Americanos (OEA), durante la Primera Conferencia de las Naciones Unidas sobre Medio Ambiente, afirmó: “Las medidas para la protección de los ecosistemas representan un lujo que las naciones latinoamericanas no deberían permitirse (Mansilla, 2003: 92). De hecho, el propio presidente Correa que pronto mostraría reticencias para mantener negociaciones con las organizaciones sociales y colectivos políticos que lo apoyaron en su ascenso al Gobierno (sobre todo el partido Pachakutik) (Rice, 2014), no dudó en afirmar ante la Asamblea Nacional Constituyente que "el mayor peligro" para el proyecto nacional liderado por el Gobierno se hallaba en "el izquierdismo y el ecologismo infantil" (Ospina Peralta, 2011: 110).

De este modo, barriendo cualquier oposición política, parecía claro que toda la narrativa construida por el Ejecutivo a favor de un nuevo horizonte sostenible en Ecuador estaba quedando soterrada por el peso de las industrias extractivas. Mientras la comunidad internacional impugnó la alternativa a la explotación de las reservas de crudo en la cuenca occidental amazónica del alto Napo (Yasuní-ITT), las industrias mineras fueron vigorizadas por los acuerdos comerciales establecidos entre el gobierno ecuatoriano y el capital inversor chino, tal como demuestra el incisivo estudio llevado a cabo por Sacher Ofensiva megaminera china en los Andes. En el altiplano andino, en la región fronteriza con Perú, "los proyectos cupríferos más prometedores del Ecuador, Mirador y Panantza-San Carlos", adquiridos en propiedad por las empresas estatales chinas Tongling Nonferrous Metals y Railways Construction Corporation (CRCC), han sacudido violentamente a las comunidades campesinas e indígenas, despojando la riqueza de sus territorios y dejando una deletérea huella ambiental para las generaciones presentes y futuras (Sacher, 2017: 338). Actividades depredadoras que, sin embargo, no han dejado de exacerbar fuertes y controvertidas tensiones sociales puesto que han sido legitimadas en nombre de los ingresos dirigidos a financiar programas sociales para erradicar la pobreza (Pérez-Rincón et al., 2019: 80-91). Así, frente a los movimientos sociales que se han levantado contra las abyectas consecuencias de la sobreexplotación territoriales, como señala Svampa, la industria extractiva ha contado con demasiada frecuencia con la aquiescencia de "trabajadores de las grandes ciudades" cuyo "imaginario desarrollista" les aleja virtualmente de los problemas ambientales o sociales derivados de la "minera, de los agronegocios, represas, fracking, entre otros". Fenómeno sociológico al que ha contribuido frecuentemente la distancia geográfica entre los "grandes nodos urbanos" y los lugares de explotación (Svampa, 2013).

Una distancia, sin embargo, contingente puesto que está siendo acortada por la fuerza intensiva de la mercantilización de los valores de uso y sus efectos socioambientales retroalimentados por el Cambio Climático. El trabajo desarrollado por un grupo de científicos en los Andes demuestra que el in- cremento demográfico, la expansión de actividades agrícolas dirigidas al mercado exterior y el "crecimiento de industrias intensivas en agua como la minería", constituyen factores orgánicamente dependientes que están agravando la escasez hídrica en Ecuador, Perú y Bolivia (Vuille et al., 2018). No se trata de un simple arcaísmo recordar aquí, tal como perspicazmente lo expresó Engels en Dialectics of Nature, que "Por cada victoria que creamos haber conseguido sobre las fuerzas de la naturaleza", ésta "acaba vengándose de nosotros. Cada victoria, es verdad, en primer lugar produce los resultados que esperábamos, pero tras éstos, tiene efectos imprevistos que a menudo acaban por destruir aquéllos" (Marx y Engels, 2010: 460-461).

En suma, la "inclusión constitucional de los derechos étnico-territoriales" en Ecuador no siempre ha tenido como consecuencia un mayor grado de "autonomía o control territorial" por parte de las "poblaciones locales". Paradójica, aunque no sorprendentemente, allí donde el Estado o las empresas gestoras han controlado directamente la actividad extractiva, la lectura constitucional (con toda su encomiable retórica sobre la inviolabilidad de los derechos de la Naturaleza) no ha dejado de ser impugnada por burócratas y administradores en nombre de las virtudes del crecimiento económico frente a las exigencias de las comunidades sociales afectadas (Carrillo, 2018b; Lalander y Kröger, 2016). Naturalmente, al no interferir en este régimen de acumulación de capital, la debilidad de la innovación institucional y la oratoria del Gobierno correísta se revelaron claramente inconsistentes. Además de los aspectos citados, otros vienen a colegir dicha afirmación.

En primer lugar, aunque "el punto de equilibrio urbanorural" fue desbordado a favor del primero a comienzos de la década de 1980, veinte años después el peso demográfico se volcó aún más hacia las ciudades donde residía el $63 \%$ de los algo más de 14 millones de habitantes. Mientras el campo se capitalizaba expulsando implacablemente a pequeños productores inviables en el competitivo mercado global, privatizando además sus bienes comunales, las receptoras áreas urbanas se transformaron en el foco de atención de las políticas públicas. Como indica el reciente informe de ONU-Hábitat, desde las últimas décadas "las ciudades han experimentado incrementos en la cobertura de servicios básicos, mejoras en la calidad de vida e inclusión social". La reducción de la pobreza, en términos generales y atendiendo a las tres regiones del país, ha mantenido un descenso más o menos sostenido del $22 \%{ }^{17}$. Sin embargo, esta tendencia que corresponde con la reducción de la pobreza a nivel nacional entre 2001 y 2014 (del 64\% se redujo al 24\%), encubre realidades societales y territoriales apenas alteradas. Durante el último año citado, "mientras a nivel nacional la pobreza por consumo" podía afectar a algo más del $25 \%$ de la población nacional, un análisis detallado a nivel cantonal y parroquial multiplica esa tasa por dos. Es decir, "a pesar del progreso generalizado" no ha dejado de persistir una clara diferenciación regional en la distribución de la pobreza: el número de pobres rurales contabilizados entre 2006 y 2014

\footnotetext{
17 ONU- Hábitat, "La prosperidad en las ciudades de Ecuador. Primer reporte de Índice de Prosperidad Urbana (CPI) para 27 ciudades ecuatorianas", CAF- Banco de Desarrollo de América Latina, 2016, pp.19 y 35
} 
era tres veces mayor que el de las ciudades, y la pobreza en la región amazónica era casi dos veces superior a la registrada en las regiones del Altiplano y la Costa ${ }^{18}$.

Naturalmente existen territorios difícilmente definibles dentro de los clásicos parámetros rural/urbano. Muchos pueblos han sido urbanizados pero también proletarizados; así por ejemplo, en el interior o en las periferias de las principales ciudades y en las ciudades intermedias han proliferado los "asentamientos precarios e irregulares" donde malviven, según informes recientes, casi tres millones de ecuatorianos y ecuatorianas ${ }^{19}$. Ante este dramático contexto social, las respuestas políticas de la "revolución ciudadana" no siempre contribuyeron a corregir el espíritu insaciable de las élites financieras. De hecho, mientras éstas continuaban drenando riqueza del suelo y del subsuelo, y el Estado intervenía con parches sociales, se propagaban ideas políticas frecuentemente ingenuas. Así, por ejemplo, al mismo tiempo que la pluma de un conspicuo representante de la institucionalidad gubernamental esbozaba un modelo de desarrollo con el fin de "construir a medio y largo plazo" una sociedad del "bio-conocimiento" (jbio-polis!), basada en la oferta de servicios "eco-turísticos comunitarios y de productos agroecológicos", en el cooperativismo y en la comunidad asociativa y, por supuesto, reduciendo la subordinación al capital financiero (Ramírez Gallegos, 2012: 36-38), este último sector representado por los siete principales bancos de Ecuador controlaba en 2014 el $87 \%$ de los activos financieros del país (Ospina Peralta, 2015: 7). ¿No deberían de ser considerados ambos aspectos contradictorios y mutuamente excluyentes si la finalidad que se persigue es levantar una economía social y una ciudadanía política más igualitaria que actúe como contratendencia al modelo hegemónico de mercado?

Mientras, como hemos observado, el urbanismo se caracterizaba por acusados niveles de desigualdad socioeconómicos, el Gobierno anhelando una acelerada transformación del país soslayaba la cruda realidad preexistente. Es significativo que desde 2012 en el municipio de San Miguel de Urcuquí (provincia de Imbabura) la administración de la "revolución ciudadana", siguiendo la estela de los utópicos de la tecnología, comenzara a planificar un proyecto urbanístico "emblemático del gobierno" denominado "la ciudad del conocimiento". Como señala un incisivo estudio etnográfico: "Se propone la construcción de una ciudad nueva sin tratar de mejorar las condiciones de las ciudades y asentamientos existentes, los cuales sufren problemas graves de urbanización, pobreza e inequidad, entre otros". Este extraño determinismo urbano de Yachay, "condensa claramente las contradicciones entre la experiencia cotidiana económica y sociopolítica en Ecuador y la ola entusiasta de transformación social que debía significar la revolución ciudadana" (Fernández González et al., 2018: 335360).

En segundo lugar, la teoría de la economía mixta keynesiana fundamentada en alianzas entre el gobierno y el sector

\footnotetext{
18 Informe: "Reporte de pobreza por consumo Ecuador 2006-2014", INEC-Banco Mundial, 2016, pp. 24 y 169.

19 Informe Nacional del Ecuador para la Tercera Conferencia de las Naciones Unidas sobre Vivienda y Desarrollo Urbano Sostenible HABITAT III, Ministerio de Desarrollo Urbano y Vivienda del Gobierno de la República del Ecuador, 2015, p. 19.
}

privado se encaminó durante el ejecutivo de Alianza País peligrosamente hacia su versión neoliberal. Tendencia que se pudo observar nítidamente en la progresiva financiarización de la salud pública a través de relaciones establecidas entre el gobierno y ciertas sociedades de capital financiero vinculadas al sistema sanitario público, algunas de ellas localizadas en jurisdicciones offshore (Iturralde, 2015). Dichas alianzas enmascaran frecuentemente, en palabras de Harvey, "las relaciones sociales y de clase que redistribuyen la riqueza y las rentas hacia los más acaudalados" (Harvey, 2017: 85). En 2014 cinco "grupos económicos oligopólicos" vinculados a la salud pública ecuatoriana obtuvieron más de mil millones de dólares en ingresos, aportando por el contrario un minúsculo 1,5\% en calidad de impuesto sobre la renta ${ }^{20}$.

Desde el último año citado, el colapso de los precios del crudo, que desencadenó una recesión del ciclo de crecimiento económico, se combinó con las implacables fuerzas de la naturaleza que dos años después actuaron en forma de terremoto sobre las provincias costeñas de Manabí y Esmeraldas. Las pérdidas humanas se cuantificaron por centenares y las materiales por más de tres mil millones. La "década ganada" de las políticas sociales de la "revolución ciudadana" entró de esta manera en una nueva fase mucho más explícita de aperturismo al capital financiero, eliminando del "escenario político", glosando a Polanyi, "las fuerzas susceptibles de revertir las reglas del mercado" (Polanyi, 2001, cit. Bull, 2016). El gobierno recurrió a la financiación del FMI y a la privatización de activos públicos, al mismo tiempo que amplió los proyectos extractivistas y reactivó el sector inmobiliario (Ortiz Crespo, 2016). Entretanto la crisis económica comenzó a atenuarse, al menos así quedó reflejado a través del tradicional e impreciso PIB que crecía en 2017 a una tasa del 3\%. Sin embargo, junto a los factores anotados, el crecimiento se sostenía en buena medida por un espectacular incremento del $59 \%$ de la demanda de crédito de los hogares, vinculado a la adquisición cotidiana de bienes y servicios ${ }^{21}$. Este ha sido, por cierto, el "mecanismo principal de la especulación" que ha caracterizado al capitalismo neoliberal, es decir, la asombrosa dilatación global del "consumo por medio del endeudamiento" (Wallerstein, 2015: 39).

Por último, el capitalismo "robinsoniano global" (Carrillo, 2018a) y su dilatada y efusiva retórica a favor de una sociedad formada por individuos "emprendedores", a través de ilusorias expectativas cristalizadas en el "autoempleo", no estuvo ausente de la agenda política del gobierno ecuatoriano. Mientras el sector de la economía informal -indiscutiblemente funcional y dependiente de la economía dominante- podía absorber al 50\% de la población ecuatoriana (Marega, 2016), toneladas de tinta institucional recalcaban con asombrosa insistencia la proyección política de una "sociedad de propietarios, productores y emprendedores"22, desplazando de este modo el

\footnotetext{
${ }^{20}$ Conviene, sin embargo, no infravalorar el aumento del gasto público destinado a la universalización sanitaria que "en 1995 representó 38\% del total, en 2007 el 24\% y en 2013 el 43\%". Véase Iturralde (2015).

21 Fuente disponible en: https://www.bce.fin.ec (consultado 5 diciembre 2018).

22 Reglamentos al Código Orgánico de la Producción, Comercio e Inversiones, Administración del Sr. Economista Rafael Correa Delgado, Presidente Constitucional de la
} 
centro de gravedad de la responsabilidad gubernamental e institucional al compromiso individual. Una retórica hegemónica -en el más estricto sentido gramsciano- que no difiere en absoluto del ideal europeo de una "sociedad de emprendedores" como obituario de la "sociedad de asalariados" (Therborn, 2014). En otros términos, y de acuerdo con Sennett, allí donde las "instituciones ya no proporcionan un marco a largo plazo, el individuo se ve obligado a improvisar el curso de su vida (improvise his or her life-narrative) o, incluso, a hacerlo sin una firme conciencia de sí mismo" (Sennett, 2006: 4). Esta "imagen de cambio enfocada al individuo", como había dicho premonitoriamente Hirschman, tiende a surgir y arraigar entre aquellas sociedades que no se hallan suficientemente integradas (Hirschman, 1958: 25-26). Ahora bien, tal vez el hecho más significativo que subyace bajo esta lógica es que el atajo individual "al drama estructural del desempleo y subempleo" constituye un factor psicosocial determinante allí donde se espera que la estructura del statu quo establecido no sea alterada (Carrión, 2016: 374).

Análogamente reaparece la economía social rebautizada ahora como "Economía Popular y Solidaria"; una presunta alternativa a las indiscreciones sociales de la economía de mercado autorregulado. Sin embargo, como en el pasado, la explosión cuantitativa de cooperativas, asociaciones y entidades que engloban este amplio y difuso sector (que al escribir esto podía absorber a un espectacular $25 \%$ de los algo más de 15 millones de ecuatorianos y ecuatorianas) (Páez Pareja, 2014), no solo no implica necesariamente un desplazamiento de la mercantilización de la economía hacia otros valores no exclusivamente económicos tales como la reciprocidad o la solidaridad, sino que con frecuencia ha actuado meramente como analgésico social o, a lo sumo, como "modelo complementario" dentro de los límites de la economía de mercado (Martínez Godoy, 2015: 160). Valores como la solidaridad o la reciprocidad se asimilan de forma inmanente, según una distorsionada visión, a las poblaciones asentadas en los heterogéneos territorios rurales. Allí se ha fusionado la Economía Popular y Solidaria con el mágico término de "emprendimiento" para corroborar un hecho manifiesto desde las décadas de las políticas de ajuste estructural, a saber, que la precarización salarial y la flexibilidad del mercado laboral agrícola conducían inevitablemente a asociarse a las personas que compartían ese mismo destino, y que no necesariamente estaban guiados por una "cooperación solidaria" (Barreno Benavides, 2018). ¿Y por qué iban a estarlo si el neoliberalismo y la instrumentalización elitaria del Estado habían cultivado convenientemente, a través de la marginación económica, política y social, una ética radicalmente individualista? El análisis sociológico llevado a cabo por Luciano Martínez sobre amplios sectores territoriales de Pichincha, Cotopaxi y Cañar, provincias situadas en el altiplano andino, colige una situación común cuyo rasgo más característico es la crisis de las "bases comunitarias y la reciprocidad" (Martínez Valle, 2017).

República del Ecuador. Registro Oficial, Quito, 2010, n. 351.
Conclusiones

A finales de la década setenta, cuando Ecuador estaba agotando los últimos años del ciclo desarrollista, penetrando azarosamente en el túnel de la deuda externa y los ecos de la neoliberalización comenzaban a sentirse continentalmente, Hirschman decidió escapar temporalmente del presente metodológico hacia una fase previa del pensamiento en la que no estaban claramente delimitadas las "fronteras interdisciplinares". Regresar "merecía la pena", decía el eminente pensador, aunque solo fuera para constatar el empobrecimiento al que la economía política estaba aproximándose, en parte "motivado por la especialización" que inhibía el desenvolvimiento intelectual libre y especulativo (Hirschman, 2014: 27). En este trabajo he intentado demostrar que, precisamente transgrediendo dichas fronteras analíticas y a través de una historización -siempre e inevitablemente selectiva-, puede escaparse de "simplificaciones" o interpretaciones "monocausales peligrosamente supersimplistas" (Harvey, 2018: 397).

En primer lugar, es poco convincente responsabilizar a las políticas del periodo desarrollista de la era del capitalismo de Estado de los graves desequilibrios internos que hoy sufre Ecuador, tal como Williamson pretende acusar a nivel continental (concretamente al periodo comprendido entre los años 1913 y 1970); intentando persuadirnos, a mi juicio acertadamente, contra otra perspectiva igualmente sesgada que, rehusando analizar la historia reciente, arguye que el origen de la desigualdad en Latinoamérica se halla irrevocablemente fosilizado en el pasado colonial (Williamson, 2015). Los argumentos de ambas posiciones no solo carecen de sólidas bases teóricas, sino que la objetivación histórica no está de su lado. Ciertamente hemos constatado que las concepciones estructuralistas colmaron ampliamente los intereses particulares de los sectores elitarios durante las dictaduras petrolíferas de las décadas sesenta y setenta del siglo pasado en el país andino. Sin embargo, este aspecto fundamental en la reconstitución económica de Ecuador implicó también una profunda alteración de la "anatomía de la sociedad civil". Aunque la dependencia del sector externo fuera a partir de este momento su rasgo más determinante $y$, sin ningún género de duda, el más duradero, las contradicciones sociales y políticas generadas por este nuevo modelo de acumulación de capital se harían patentes durante y después de este periodo. Las organizaciones sindicales y los colectivos sociales vinculados al universo indígena actuarían a partir de ahora como "contramovimientos" políticos, intentando modular las tensiones entre capitalismo y democracia.

Segundo, las políticas deliberadamente antisociales de ajuste estructural, de acuerdo con la doctrina económica estándar, provocaron nuevas contradicciones sistémicas, como por ejemplo, la dolarización que contrajo la autonomía de la política pública. De este modo, las asignaciones de la deuda externa se combinaron con las políticas neoliberales para desgastar o, más preciso, instrumentalizar la política estatal en favor de una minoritaria clase social, al mismo tiempo que se abonó convenientemente la solidaridad funcionalista de la 
cooperación internacional. Su consecuencia más dramática e inminente fue el incremento espectacular de la pobreza. Las ciudades absorbían constantemente a las poblaciones expulsadas y marginadas de los territorios rurales donde una exigua reforma agraria había limitado severamente las condiciones económicas para la reproducción social. Así, los pobres rurales ubicados en las periferias urbanas o en los barrios degradados, fuera de las áreas gentrificadas de las principales ciudades del país, sobrevivían o malvivían dentro del cada vez más dilatado sector informal de la economía. Mientras el mundo rural se capitalizaba transformando los valores de uso en valores de cambio y privatizando los bienes comunes, el número de trabajadores rurales proletarizados no cesaba de crecer; la "frontera étnica" continuaba persiguiendo a las poblaciones indígenas "como su propia sombra" a lo "ancho y ajeno" del siempre convulso e impreciso Estado nacional (Guerrero, 1997). La espectacular emigración internacional a la que se vieron forzados miles de ecuatorianos y ecuatorianas constituye uno de los rasgos más amargos de las elegantes ecuaciones neoconservadoras (García Martínez, 2019).

Tercero, frente a este vetusto escenario social provocado por la búsqueda de la eficiencia económica, la movilización social de indios y su proyección orgánica en el partido político Pachakutik, durante la década de 1990, provocó sin duda un alud de esperanzas entre las poblaciones secularmente marginadas y excluidas de la esfera pública. De hecho, esta energía social y política fue determinante para menoscabar el asalto neoliberal. Así, durante la primera década del presente siglo parecía que la política pública estaba regresando con el fin de estabilizar la irracionalidad del mercado autorregulado. La irrupción política de la "revolución ciudadana" de Alianza País enarbolando un ambiguo programa entre keynesianismo destilado y un socialismo más retórico que político fue recibida, en principio, con un portentoso entusiasmo social. Sin embargo, en último término, las expectativas de transformación radical de la "revolución ciudadana" quedaron fuertemente circundadas por el tour de force entre una política económica procíclica cimentada en una nueva fase neoextractivista, vigorizada por las curvas de crecimiento del asombroso mercado chino, y las tensiones y contradicciones subyacentes de la economía global. Pero también por el ánimo que según Hirschman orientaba a las reformas políticas emprendidas "desde arriba", las cuales "a menudo no tienen conexión con la realidad" y son "fáciles de mutilar", especialmente allí donde la política no ha sido capaz de contener el espíritu secular de las elites latinoamericanas, siempre reacias a "dar algo para no perderlo todo" (Hirschman, 1979: 96).

Los acontecimientos políticos que al escribir estas líneas han exacerbado a las clases sociales más desfavorecidas de Ecuador no constituyen, empero, un fenómeno social que pueda asociarse exclusivamente a la administración del Gobierno correísta, aunque obviamente su legado político no puede menospreciarse. Su sucesor en el ejecutivo desde 2017, Lenín Moreno, ha demostrado con solvencia su adhesión incondicional a esas élites señaladas por Hirschman, que junto a las instituciones globales del capitalismo neoliberal no desestiman la imposición de políticas de austeridad a las bases del cuerpo social. Mientras el Gobierno solicitaba ampliar la deuda externa con el fin de corregir los peligros del déficit fiscal a través del generoso suministro de los acreedores internacionales, la verdadera magnitud de la compleja problemática de la economía política del país no solo se deja irresuelta sino que dramáticamente podría verse agravada. En términos generales, una combinación de economía que no ha crecido en la dirección opuesta del sector externo de materias primas, dejando un legado execrable de pérdidas en biodiversidad y recursos naturales, con una balanza comercial claramente inclinada hacia la importación de productos incluso básicos, sumado a una pérdida más que considerable de autonomía fiscal severamente afectada por la dolarización, confluye con un cuerpo social desgastado por décadas de racismo, austeridad y servidumbre. Pero esta sombría realidad no es exclusiva de Ecuador. Las alternativas políticas e intelectuales al fetichismo de mercado han sido claramente inconsistentes, como lo demuestran las incertidumbres creadas por la nueva ofensiva de la derecha en la región. Sin duda, como he abordado en trabajos anteriores, no estamos exclusivamente ante un entreacto de las singularidades políticas latinoamericanas dada la turbulenta naturaleza de la crisis de la economía mundial y el aislamiento hegemónico de las políticas antisistémicas de izquierdas (Carrillo, 2018b). Y sin embargo, como dijo con admirable claridad George Lichtheim al describir la década setenta como una nueva fase de la "economía planetaria" dominada por una elite de administradores tecnocráticos que "han dejado atrás el Estado nacional", la historia "no depositará jamás a sus pasajeros en el destino que han elegido, salvo que ellos mismos se hagan cargo de la máquina" (Lichtheim, 1972: 18). Tal vez, la extraordinaria y dramática imagen de las calles de Quito, una y otra vez jalonadas de indios (en ocasiones por los que dicen representar sus intereses) reacios a dejar la historia en manos ajenas, constituya un acicate para aquellos que consideran que el mundo por sí solo no podrá escapar de los márgenes impuestos por el fetichismo economicista. 
Bibliografía

ABRAMS, Philip (1988): "Notes on the Difficulty of Studying the State”, Journal of Historical Sociology, 1 (1), pp. 58-89.

ACOSTA, Alberto (2005): "El aporte de las remesas para la economía ecuatoriana", Informe: Expert group meeting on international migration and development in Latin America and the Caribbean, Population Division Department of Economic and Social Affairs United Nations Secretariat, Mexico.

ALMEIDA VINUEZA, José (2003): "Identidades en el Ecuador. Un balance antropológico", en Simón Pachano (ed.), Ciudadanía e identidad, FLACSO, Quito, pp. 83-142.

ANDRADE A., Pablo (2009): Democracia y cambio político en el Ecuador. Liberalismo, política de la cultura y reforma institucional, Universidad Andina Simón Bolívar y Corporación Editora Nacional.

AYALA MORA, E. (2002): Ecuador desde 1930, en Leslie Bethell (Ed.), Historia de América Latina. Los países andinos desde 1930, vol. 16, Crítica, Serie Mayor, Barcelona, pp. 259-300.

BARRENO BENAVIDES, Luis E. et al. (2018): "La precarización salarial en la actividad agrícola y su incidencia en la política de economía popular y solidaria en el Ecuador", Economía, vol. XLI, n.81, pp. 47-67.

BRETÓN, Víctor (2001): Cooperación al desarrollo y demandas étnicas en los Andes ecuatorianos, FLACSO/Edicions de la Universitat de Lleida, Quito/Lleida.

BRETÓN, Víctor (2013): "Etnicidad, desarrollo y buen vivir: Reflexiones críticas en perspectiva histórica", Revista Europea de Estudios Latinoamericanos y del Caribe 95, pp.71-95.

BRETÓN, Víctor y MARTíNEZ NOVO, Carmen (2015): “Políticas de reconocimiento neoliberales y posneoliberales en Ecuador: continuidades y rupturas", Quaderns, 31, pp. 25-49.

BRETÓN, Víctor (2017): La dimensión política de la identidad étnica en los Andes, en Bretón, Víctor y Vilalta, María José (eds.), Poderes y personas. Pasado y presente de la administración de poblaciones en América Latina, Icaria, Institut Català d'Antropologia, Barcelona, pp. 147-173.

BULL, Malcolm (2016): “Ablandar el Estado", New Left Review 100, pp. 3959.

BURCHARDT, Hans-Jürgen et al. (2016): Nada dura para siempre. Neo-extractivismo tras el boom de las materias primas, Universidad Andina Simón Bolívar, Sede Ecuador, International Center for Development and Decent Work (ICDD) Universität Kassel.

BURCHARDT, Hans-Jürgen (2017): "Neoextractivismo y desarrollo: fuerzas y límites", Revista Brasileira de Planejamento e Desemvolvimento, 6 (3), pp. 340-367.

CARRILLO, Germán (2014): Desarrollo Rural y Cooperativismo agrario en Ecuador. Trayectorias históricas de los pequeños campesinos en la economía global, MAGRAMA, Madrid.

CARRILLO, Germán (2017): Revoluciones y reformas agrarias durante el largo siglo XX, en Germán Carrillo y Justo Cuño (Compiladores): Historia agraria y políticas agrarias en España y América Latina desde el siglo XIX hasta nuestros días, Ministerio de Agricultura y Pesca, Alimentación y Medio Ambiente, Madrid, 2017, pp. 147-238.

CARRILLO, Germán (2018a): “La desintegración civil del demos moderno. Sobre la naturaleza de la ruptura política en las sociedades financiarizadas", Intersticios: Revista Sociológica de Pensamiento Crítico, vol. 12 (2), pp. 5-23.

CARRILLO, Germán (2018b): "Transiciones y continuidades: una interpretación socio-histórica acerca de la crisis económica de América Latina", La Razón Histórica. Revista hispanoamericana de Historia de las Ideas, 41, pp. 168-198.
CARRIÓN SÁNCHEZ, Diego (2016): Estado, conflictividad y valores de uso alternativos: petróleo, minería y turismo, en Hans-Jürgen Burchardt et al., Nada dura para siempre..., cit. pp. 355-390.

CASALS, Juan F. (1965): Ecuador 1964, en Delgado, Óscar (ed.), Reformas agrarias en la América Latina. Procesos y perspectivas, Fondo de Cultura Económica, México-Buenos Aires, pp.675-687.

CEVALLOS, Carlos G. (1999): "El sector informal urbano del ecuador: una visión de su magnitud actual y la particular situación de la mujer en éste", América Latina Hoy, 22, pp. 43-47.

CIDA (1965): Tenencia de la tierra y desarrollo socioeconómico del sector agrícola: Ecuador, PAU, Washington.

CLARK, T. D. and NORTH, L. (2018): "The Limits of Democratization and Social Progress: Domination and Dependence in Latin America", in Clark, Timothy D. and North, Liisa (eds.), Dominant Elites in Latin America: From Neo-Liberalism to the 'Pink Tide',Palgrave Macmillan.

CORAGGIO, José Luis (2016): “La Economía Social y Solidaria (ESS): Niveles y alcances de acción de sus actores. El papel de las Universidades", en Carlos Puig (coord.), Economía Social y Solidaria: conceptos, prácticas y políticas públicas, Universidad del País Vasco, Instituto de Estudios sobre desarrollo y cooperación internacional, Bilbao, pp. 15-39.

CORREA, Rafael (2009): Ecuador: de banana republic a la No república, Debate ed., Quito.

COTLER, Julio (2005): “Bolivia, Ecuador, Perú, 2003-2005: ¿tempestad en los Andes?, Real Instituto Elcano de Estudios Internacionales y Estratégicos, Área América Latina-DTn. 51.

CUEVA, Agustín (1998): El desarrollo del capitalismo en América Latina, Siglo XXI editores, México.

DA ROS, Giuseppina (2007): "El movimiento cooperativo en el Ecuador. Visión histórica, situación actual y perspectivas", CIRIEC-España, Revista de Economía Pública, Social y Cooperativa, 57, pp. 249-284.

DAVIDSON, N. (2013): Transformar el mundo. Revoluciones burguesas y revolución social, Pasado\&Presente, Barcelona.

DAVIS, Mike (2004): "Planeta de ciudades-miseria. Involución urbana y proletariado informal", New Left Review, 26, pp. 5-34.

DAVIS, Mike (2014): Planeta de ciudades miseria, Akal, Madrid.

DIETERICH, S. H. (2006), La democracia participativa. El Socialismo del siglo $X X I$, Gara Egunkaria.

FARRELL, Gilda (1985): El movimiento sindical frente a la segmentación tecnológica y salarial del mercado de trabajo, en Louis Lefeber (ed.), La economía política del Ecuador. Campo, región, nación, Corporación Editora Nacional, Quito, pp. 337-367.

FERNÁNDEZ GONZÁLEZ, Miquel; CADENAS ÁLVAREZ, M. y PURCELL, T. (2018): “Urbanismo utópico, realidades distópicas: una etnografía (im) posible en Yachay, "ciudad del conocimiento", Revista do Centro em Rede de Investigação em Antropologia, 22 (2), pp. 335-360.

FONTAINE, Guillaume (2002): “Sobre bonanzas y dependencia Petróleo y enfermedad holandesa en el Ecuador", Iconos. Revista de Ciencias Sociales, 13, pp. 102-110.

FONTANA, Josep (2011): Por el bien del imperio. Una historia del mundo desde 1945, Pasado\&Presente, Barcelona.

FONTANA, Josep (2017): El siglo de la revolución. Una historia del mundo desde 1914, Crítica, Barcelona.

GABRIEL PALMA, José (2014): "Latin America's social imagination since 1950. From one type of 'absolute certainties' to another- with no (far more creative) 'uncomfortable uncertainties' in sight", Cambridge Working Papers in Economics.

GARCÍA MARTíNEZ, José María (2019): “Crónicas del asedio a la fortaleza: la migración en la era de la globalización neoliberal. El caso de estudio de Zamora Chinchipe (Ecuador) como reflejo de un fenómeno a escala global", La Razón Histórica, 43, pp. 134-167.

GÖRAN, Therborn (2014): “ ¿Nuevas masas críticas? Las bases sociales de la resistencia", New Left Review, 85, pp. 5-17. 
GRAMSCl, Antonio (1981): Cuadernos de la cárcel, Ediciones Era, Tomo 1, Q 1, (Edición crítica del Instituto Gramsci a cargo de Valentino Gerra$\operatorname{tana).}$

GUERRERO, A. (2010): Administración de poblaciones, ventriloquía y transescritura: análisis históricos, estudios teóricos, FLACSO, Quito e Instituto de Estudios Peruanos, Lima.

GUERRERO, A. (1997): "Poblaciones indígenas, ciudadanía y representación", Nueva Sociedad, 150, pp. 98-105.

GUERRERO, A. (1988): El proceso de producción inmediato de la hacienda, en Chiriboga, M. (ed.), El problema agrario en el Ecuador, ILDIS, Quito.

HARVEY, D. (2005): A brief history of neoliberalism, Oxford University Press, New York.

HARVEY, David (2014): Seventeen Contradictions and The End of Capitalism, Great Britain: Profile Books.

HARVEY, David (2016): El enigma del capital y las crisis del capitalismo, Akal, Madrid.

HARVEY, David (2017): El cosmopolitismo y las geografías de la libertad, Akal, Madrid.

HARVEY, David (2018): Senderos del mundo, Akal, Madrid.

HIRSCHMAN, Albert O. (1958): The Strategy of Economic Development,

Yale University Press, Inc., New Haven.

HIRSCHMAN, Albert O. (1979): The Turn to Authoritarianism in Latin America and the Search for Its Economic Determinants, en David Collier, (ed.), New Authoritarianism in Latin America, Princeton University Press, New Jersey, pp.61-98.

HIRSCHMAN, Albert O. (1984): De la economía a la política y más allá, Fondo de Cultura Económica, México, D. F.

HIRSCHMAN, Albert O. (1985): "Against parsimony Three Easy Ways of Complicating some Categories of Economic Discourse", Economics and Philosophy, 1, pp. 7-21.

HIRSCHMAN, Albert O. (1987): "La economía política del desarrollo latinoamericano", El Trimestre Económico, 216, vol. 54 (4), pp. 769-804.

HIRSCHMAN, Albert O. (2014): Las pasiones y los intereses. Argumentos políticos en favor del capitalismo previo a su triunfo, Capitán Swing, Madrid.

HOBSBAWM, Eric (1995): Historia del siglo XX, Crítica, Barcelona.

HOBSBAWM, Eric (2000): "La izquierda y la política de identidad", New Left Review 0, (2a época), pp. 114-125.

HOBSBAWM, Eric (2012): Cómo cambiar el mundo. Marx y el marxismo 1840-2011, Crítica, Barcelona.

HUDSON, Michael (2010): "El Sur tiene que prescindir del modelo del Norte", Sinpermiso, Disponible en: http://www.sinpermiso.info/sites/default/files/textos//hudson2.pdf.

HUDSON, Michael (2018): Matar al huésped. Cómo la deuda y los parásitos financieros destruyen la economía global, Capitán Swing, Madrid.

ITURRALDE, P.J. (2015): Privatización de la salud en Ecuador. Estudio de la interacción pública con clínicas y hospitales privados, Centro de Derechos Económicos y Sociales-CDES, Quito.

JOKISCH, Brad y KYLE, David (2005): "Las transformaciones de la migración transnacional del Ecuador, 1993-2003", en Gioconda Herrera et al., La migración ecuatoriana transnacionalismo, redes e identidades, FLACSO, Quito, pp. 57-69.

KAY, Cristóbal (1998): “EEl fin de la reforma agraria en América Latina?", Revista Mexicana de Sociología, 60 (4), pp. 63-98.

LALANDER, R. y KRÖGER, M. (2016): "Extractivismo y derechos étnico-territoriales de jure y de facto en Latinoamérica: ¿cuán importantes son las constituciones?", CLAES, Centro Latino Americano de Ecología Social, 23, pp. 1-21.

LANDÁZUR, Helena y JIJÓN, Carolina (1988): El medio ambiente en Ecuador, Instituto latinoamericano de Investigaciones sociales, ILDIS, 1988.

LARREA, Carlos (2008): "Tenencia de la tierra, cambios agrarios y etnicidad indígena en el Ecuador: 1954-2000", en Liisa North y John D. Cameron, (eds.), Desarrollo rural y neoliberalismo. Ecuador desde una perspec- tiva comparativa, Universidad Andina Simón Bolívar, Sede Ecuador, Corporación Editora Nacional, Quito, pp. 129-146.

LARREA, Carlos (2008): “Petróleo, pobreza y empleo en el Ecuador: de la bonanza a la crisis", en Hans-Jürgen Burchardt et al. (2016), Nada dura para siempre. Neo-extractivismo tras el boom de las materias primas, Universidad Andina Simón Bolívar, Sede Ecuador, International Center for Development and Decent Work (ICDD) Universität Kassel, pp. 131-156.

LAVINAS, Lena (2014): "La asistencia social en el siglo XXI", New Left Review, 84, (2a época), pp. 7-48.

LEFEBER, Louis (1985): “El fracaso del desarrollo: Introducción a la economía política del Ecuador", en Louis Lefeber (ed.), La economía política del Ecuador. Campo, región, nación, Corporación Editora Nacional, Quito, pp.17-33.

LEÓN TRUJILLO, Jorge (2010): “Las organizaciones indígenas y el gobierno de Rafael Correa", Iconos. Revista de Ciencias Sociales, 37, Quito, pp. 13-23.

LICHTHEIM, George, El imperialismo, Alianza Ed., Madrid, 1972.

LÖWY, Michael (2011): "Laboratorio continental", New Left Review, 68, pp. 123-131.

MANSILLA, H. C. F. (2003). “Desarrollo como imitación. La marcha victoriosa de la racionalidad instrumentalista en el Tercer Mundo", Boletín de Psicología, 78, pp. 81-99.

MAQUIAVELO, Nicolás (2000): El príncipe, Espasa Calpe, Madrid.

MARCHENA FERNÁNDEZ, Juan J. (2006): “La voz de los cerros y los páramos. Los universos indígenas andinos en su lucha por la educación y el respeto de sus identidades", Historia de la educación colombiana, 9, pp. 9-71.

MAREGA, Magali (2016): "Trabajo y sindicalismo en tiempos del neo-extractivismo: el caso Ecuador", en Hans-Jürgen Burchardt et al., Nada dura para siempre. Neo-extractivismo tras el boom de las materias primas, Universidad Andina Simón Bolívar, Sede Ecuador, International Center for Development and Decent Work (ICDD) Universität Kassel, pp. 225-251.

MARTÍNEZ GODOY, Diego (2015): “Entre economia social y economia popular: confusiones y desaciertos políticos en el Ecuador del Buen Vivir", Eutopía, 7, pp.147-161.

MARTÍNEZ NOVO, Carmen (2017): “Censos de población y administración de la diversidad étnica en el Ecuador", Víctor Bretón y María José Vilalta (eds.), Poderes y personas. Pasado y presente de la administración de poblaciones en América Latina, Icaria, Institut Català d'Antropologia, Barcelona, pp.125-144.

MARTÍNEZ VALLE, Luciano (2007): "Precariedad y desigualdad social en el agro ecuatoriano", en Víctor Bretón et al., Ciudadanía y exclusión: Ecuador y España frente al espejo, Catarata, Madrid, pp. 203-222.

MARTíNEZ VALLE, Luciano (2008): “Respuestas endógenas de los campesinos frente al ajuste estructural. Ecuador desde una perspectiva andina comparativa", en Liisa North y John D. Cameron, Desarrollo rural y neoliberalismo. Ecuador desde una perspectiva comparativa, Corporación Editora Nacional, pp.105-127.

MARTÍNEZ VALLE, Luciano (2014): "La concentración de la tierra en el caso ecuatoriano: Impactos en el territorio", en Albert Berry et al., La concentración de la tierra. Un problema prioritario en el Ecuador contemporáneo, Abya Yala, Quito, pp. 43-62.

MARTÍNEZ VALLE, Luciano (2016): "Territorios campesinos y reforma agraria: el caso de las cooperativas indígenas de la sierra ecuatoriana", Mundo Agrario, 35, pp. 1-17.

MARTÍNEZ VALLE, Luciano (2017): "La crisis de los procesos de cooperación y solidaridad entre el campesinado andino de Ecuador", en Marcos A. Saquet y Adilson Alves (comp.), Processos de cooperaçao e solidariedade na America Latina, Consequência, pp.13-35.

MARX, K. y ENGELS, F. (2010): Collected Works, vol. 25, Engels, Lawrence \& Wishart Electric Book. 
MARX, K. y ENGELS, F. (2011): Manifiesto comunista, Centro de Estudios Socialistas Carlos Marx, México.

NAYYAR, Deepak (2007): "Globalization and free trade: theory, history, and reality", en Anwar Shaikh (coord.), Globalization and the Myths of Free Trade History, theory, and empirical evidence, Routledge, USA y Canada, pp. 69-84.

NORTH, Liisa L. (2008): "Diversificación rural endógena. Empresas textiles familiares en Pelileo, Tungurahua", en Liisa North y John D. Cameron (eds.), Desarrollo rural y neoliberalismo. Ecuador desde una perspectiva comparativa, Corporación Editora Nacional, pp. 255-276.

NORTH, Liisa L. y CAMERON, John D. (eds.) (2008): Desarrollo rural y neoliberalismo. Ecuador desde una perspectiva comparativa, Corporación Editora Nacional.

OCAMPO, José A. (2013): The history and challenges of Latin American Development, United Nations, Santiago, Chile.

OCAMPO, José A. (2014): "La crisis latinoamericana de la deuda a la luz de la historia", en José A. Ocampo et al., La crisis latinoamericana de la deuda desde la perspectiva histórica, CEPAL, Santiago de Chile, pp. 19-51.

ORTIZ CRESPO, S. (2016): "Los laberintos de la Revolución ciudadana en Ecuador", Nueva Sociedad, 26, pp.84-97.

OSPINA PERALTA, Pablo (2011): "Corporativismo, Estado y revolución ciudadana. El Ecuador de Rafael Correa", en Christian Büschges; Olaf Kaltmeier y Sebastian Thies (eds.), Culturas políticas en la región andina. Actores, prácticas y discursos, Iberoamericana/Vervuert, Madrid/ Frankfurt am Main, pp. 85-116.

OSPINA PERALTA, Pablo (2015): Crisis y tendencias económicas en el Ecuador de Rafael Correa. Informe de coyuntura, abril de 2015, Comité Ecuménico de Proyectos (CEP), Quito.

PÁEZ PAREJA, José R. (2014): Balance Social de las cooperativas en Ecuador: Modelo y primeros resultados agregados, en José Ramón Páez Pareja (comp.), Serie Estudios sobre la economía popular y solidaria Contextos de la "Otra Economía", Quito, pp. 41-82.

PALMA, José Gabriel (2005): "Four sources of 'de-industrialisation' and a new concept of the Dutch-Disease", en José A. Ocampo (ed.), Beyond Reforms. Structural Dynamics and Macroeconomic Vulnerability, United Nations Economic Commission for Latin America and the Caribbean (ECLAC), Washington, DC, pp. 71-116.

PALMA, José Gabriel (2014): "Latin America's social imagination since 1950. From one type of 'absolute certainties' to another- with no (far more creative) 'uncomfortable uncertainties' in sight", Cambridge Working Papers in Economics.

PANITCH, Leo and KONINGS, Martijn (2009): "Myths of Neoliberal Deregulation", New Left Review, 57, pp.67-83.

PAZY MIÑO C., Juan J. (2016): "Trabajadores y movimiento obrero. Elementos históricos para una economía política sobre el trabajo en Ecuador", Historia y Economía, junio/julio, pp. 1-24.

PÉREZ-RINCÓN, M., VARGAS-MORALES J., MARTÍNEZ-ALIER， J. (2019): "Mapping and Analyzing Ecological Distribution Conflicts in Andean Countries", Ecological Economics, 157, pp. 80-91.

PETRAS, James y VELTMEYER, Henry (1995): “La recuperación económica de América Latina. El mito y la realidad", Nueva Sociedad, 137, pp. 164179.

POLANYI, Karl (2001): The Great Transformation. The Political and Economic Origins of Our Time, Beacon Press, Boston Massachusetts.

RAMÍREZ GALLEGOS, R. (2012): Socialismo del sumak kawsay o biosocialismo republicano, Secretaría Nacional de Educación Superior, Ciencia, Tecnología e Innovación, Quito.

RICE, Roberta (2014): "Indigenous Political Engagement: A Second, More Meaningful Chance at Incorporation", lasaforum, vol. xlv, issue 1, pp. 13-14.

SACHER, William (2017): Ofensiva megaminera china en los Andes. Acumulación por desposesión en el Ecuador de la 'Revolución Ciudadana', Abya Yala, Quito.
SACHS, J. D. y WARNER, A. M. (1997): Natural Resource Abundance and Economic Growth, Center for International Development and Harvard Institute for International Development. Harvard University, Cambridge MA.

SALGADO, Germánico (1987): "Ecuador: Crisis y políticas de ajuste. Su efecto en la agricultura", Revista de la CEPAL, 33, pp. 135-152.

SALAMON, Lester M. (1994): "The Rise of the Nonprofit Sector", Foreign Affairs, 73 (4), pp. 109-122.

SAMANAMUD, Germán T. (2014): "China en América Latina: los casos de Ecuador y Perú entre los años 2009-2012, ¿es posible una apuesta hacia el futuro?", Anuario Mexicano de Derecho Internacional, vol. XIV, pp. 221-260.

SÁNCHEZ-PARGA, José (1996): Población y pobreza indígenas, CAAP- Centro Andino de Acción Popular, Quito.

SÁNCHEZ-PARGA, José (2006): "Desarrollo local: teoría, crítica y cuestionamientos", Universitas. Revista de ciencias sociales y humanas, 8, pp. 81-113.

SÁNCHEZ-PARGA, José (2009): Qué significa ser indígena para el indígena. Más allá de la comunidad y la lengua, Abya Yala, Quito.

SÁNCHEZ-PARGA, José (2011): "Discursos retrovolucionarios: sumak kawsay, derechos de la naturaleza y otros pachamamismos", Ecuador Debate, 84, pp. 31-50.

SENNETT, Richard (2006): The culture of the new capitalism, Yale University Press New Haven \& London.

SHAIKH, Anwar (coord.) (2007): Globalization and the Myths of Free Trade History, theory, and empirical evidence, Routledge, USA y Canadá.

SLIPAK, Ariel M. (2014): "América Latina y China: ¿Cooperación Sur-Sur o Consenso de Beijing"?, Nueva Sociedad, 250, pp. 102-113.

STREECK, Wolfgang (2011): "La crisis del capitalismo democrático", New Left Review, 71, pp.5-26.

SVAMPA, Maristella, "Consenso de los Commodities y lenguajes de valoración en América Latina", Nueva Sociedad, 244, pp. 30-46

VELTMEYER, Henry (2008): La dinámica de las ocupaciones de tierras en América Latina, en Sam Moyo y Paris Yeros (coords.), Recuperando la tierra. El resurgimiento de movimientos rurales en África, Asia y América Latina, CLACSO, Buenos Aires, pp. 301-333.

VUILLE, Mathias et al. (2018): "Rapid decline of snow and ice in the tropical Andes-Impacts, uncertainties and challenges ahead", Earth-Science Reviews, 176, pp. 195-213.

WALLERSTEIN, Immanuel (2015): La crisis estructural, o por qué los capitalistas ya no encuentran gratificante al capitalismo, en Wallerstein et al., ¿Tiene futuro el capitalismo?, Siglo XXI, México D.F., pp.15-46.

WEBER, Max (1978): Economy and Society. An outline of interpretive sociology, Guenther Roth y Clauss Wittich (eds.), University of California Press. Disponible en: https://archive.org/details/MaxWeberEconomyAndSociety/page/n1

WHITEHEAD, Laurence (2002): "Bolivia, 1930-c. 1990", en Leslie Bethell (ed.), Historia de América Latina. Los países andinos desde 1930, vol. 16, Crítica, Serie Mayor, Barcelona, pp.105-169.

WILLIAMSON, Jeffrey G. (2015): "Latin American Inequality: Colonial origins, commodity booms, or a missed 20th century leveling?" Working Paper 20915, National Bureau of Economic Research, Cambridge. Disponible en: http://www.nber.org/papers/w20915

WORLD BANK (2004): "Ecuador Poverty Assessment", Poverty Reduction and Economic Management Sector Unit Latin America and the $\mathrm{Ca}-$ ribbean Region Washington, D. C. 